\title{
Genomic and epigenomic adaptation in SP-R210 (Myo18A) isoform- deficient macrophages
}

1 Eric Yau ${ }^{1, \wedge}, *$, Yan Chen ${ }^{1,2, \wedge}$, Chunhua Song ${ }^{3,4}$, Jason Webb ${ }^{1}$, Marykate Carillo1, Yuka Imamura

2 Ikawasawa ${ }^{5}$, Zhenyuan Tang ${ }^{2}$, Yoshinori Takahashi ${ }^{2}$, Todd M Umstead ${ }^{1}$, Sinisa Dovat ${ }^{2}$, Zissis C.

3 Chroneos $^{1, *}$

4 Department of Pediatrics and Microbiology and Immunology, Pulmonary Immunology and

5 Physiology Laboratory, Pennsylvania State University College of Medicine, Pennsylvania, USA

62 Department of Pediatrics, Union Hospital, Tongji Medical College, Huazhong University of Science

7 and Technology, Wuhan, China

$8{ }^{3}$ Department of Pediatrics, Division of Pediatric Hematology and Oncology, Pennsylvania State

9 University College of Medicine, Pennsylvania, USA

$10{ }^{4}$ Department of Internal Medicine, Ohio State University College of Medicine, Columbus, Ohio, USA

$11{ }^{5}$ Department of Pharmacology and Biochemistry and Molecular Biology, Institute for Personalized

12 Medicine, Pennsylvania State University College of Medicine, Pennsylvania, USA

*Correspondence:

15 Eric Yau: eyau@pennstatehealth.psu.edu, and

16 Zissis C. Chroneos: zchroneos@pennstatehealth.psu.edu

17 ^Authors with equal contribution

19 Keywords: Macrophage Phenotype and function, PU.1 SP-R210 (Myo18A) isoforms, Influenza, Anti20 viral inflammation. 


\section{Abstract}

23 Macrophages play fundamental roles in regulation of inflammatory responses to pathogens, 24 resolution of inflammation and tissue repair, and maintenance of tissue homeostasis. The long (L) 25 and short (S) isoforms of SP-R210/MYO18A, a macrophage receptor for surfactant protein A (SP-A) 26 and $\mathrm{C} 1 \mathrm{q}$, regulate basal and inflammatory macrophage phenotype at multiple gene expression, 27 translational, and subcellular levels in addition to their SP-A and C1q-mediated functions; disruption 28 of $L$ renders macrophages hyper-inflammatory, although the underlying mechanism had previously 29 been unexplored. We asked whether disruption of the $L$ isoform led to the hyper-inflammatory state 30 via alteration of global genomic responses. RNA sequencing analysis of SP-R210 (DN) macrophages

31 revealed basal and influenza induced upregulation of genes associated with inflammatory pathways, 32 including TLR, RIG-I, NOD, and cytoplasmic DNA signaling, whereas knockdown of both SP-R210 33 isoforms ( $L$ and S) only resulted in increased RIG-I and NOD signaling. Chromatin immunoprecipitation 34 sequencing (ChIP-seq) analysis showed increased genome-wide deposition of the pioneer 35 transcription factor PU.1 in SP-R210L(DN) compared to WT cells. ChIP-seq analysis of histone H3 36 methylation showed alterations in both repressive (H3K9me3 and H3K27me3) and transcriptionally 37 active (H3K9me3) histone marks. Influenza A virus (IAV) infection, which stimulates an array of 38 cytosolic and TLR-mediated antiviral mechanisms, resulted in differential redistribution between 39 proximal promoter and distal sites and decoupling of PU.1 binding from Toll-like receptor regulated 40 gene promoters in SP-R210 (DN) cells. Our findings suggest that SP-R210L-deficient macrophages are 41 poised with an open PU.1-primed chromatin conformation to rapidly respond to inflammatory and 42 metabolic stimuli. 


\section{Introduction}

Macrophage functions are dynamic, alternating between pro-inflammatory responses to pathogens and stress, and anti-inflammatory responses to alleviate injury to facilitate tissue repair (Sica and Mantovani, 2012, Italiani and Boraschi, 2014, Stout, et al., 2005). Controlling this plasticity is particularly important in the context of alveolar macrophages, the resident immune cell of the lungs (Hussell and Bell, 2014, McQuattie-Pimentel, et al., 2021). As our lungs are exposed to pollutants, pathogens, and particulates on a daily basis that can result in injury, infection, and damage, this fluidity to regulate inflammatory activation state is particularly important for alveolar macrophages to maintain lung homeostasis and avoid overt inflammation (Upham, et al., 1995, Kobzik, et al., 1990). GM-CSF, the transcription factors PU.1 and PPAR $\gamma$, and the local microenvironment consisting of surfactant proteins and lipids drive alveolar macrophage (AM) development, differentiation, and function (McQuattie-Pimentel, et al., 2021, Shibata, et al., 2001, Baker, et al., 2010, Chroneos, et al., 2010, Guilliams, et al., 2013, Bates, et al., 1997, Schneider, et al., 2014).

Unlike circulating monocyte-derived macrophages, alveolar macrophages are derived from monocyte progenitors in the yolk sac and fetal liver, which then migrate to the lung during fetal development (Guilliams, et al., 2013, Tan and Krasnow, 2016). Early studies depleting alveolar macrophages in mice showed that they play a critical role in pathogen clearance, similar to circulating monocyte-derived macrophages. AMs secrete anti-microbial cytokines such as type I IFNs, phagocytose pathogens, and act as antigen presenting cells to bridge the innate and adaptive immune systems (He, et al., 2017, Kirby, et al., 2009). Depletion of alveolar macrophages also results in overt inflammatory responses in mice exposed to sensitizing proteins, in particular through secretion of cytokines like TGF $\beta$, IL-10, and prostaglandins (Roth and Golub, 1993). Alveolar macrophages are critical for host survival and resolution of influenza infection (Schneider, et al., 2014, Purnama, et al., 2014, Halstead, et al., 2018, Halstead and Chroneos, 2015). AMs are thus critical in maintaining the anti-inflammatory state of the lung under normal conditions, and to resolve inflammation that occurs during pulmonary infections caused not only by the pathogen itself, but also by the host inflammatory response.

The unique microenvironment of the lung alveolus consists of surfactant proteins that work in concert with alveolar macrophages to regulate immune balance, host defense, and tissue homeostasis (Chroneos, et al., 2010, Casals, et al., 2019, Minutti, et al., 2017). Surfactant proteins are 
part of the lipoprotein surfactant complex that reduces alveolar surface tension to maintain alveolar gas-exchange, alveolar stability, and alveolar recruitment during breathing (Canadas, et al., 2020, Autilio and Perez-Gil, 2019). There are two hydrophobic (SP-B, SP-C) and two hydrophilic lipid-binding (SP-A, SP-D) surfactant proteins, all having amino-terminal domains that are important for oligomerization into lipid-dependent and lipid-independent supramolecular structures. SP-B and SP$\mathrm{C}$ are critical for the formation of the surface tension lowering surfactant monolayer at the air-liquid interface, whereas SP-A and SP-D modulate ultrastructural organization of the surfactant phospholipid sub-phase. Within this milieu, the surfactant proteins enhance pathogen clearance and coordinate immune and metabolic functions of alveolar macrophages, alveolar epithelial cells, and their cross-talk with innate and adaptive immune cells. Under basal conditions, SP-A maintains alveolar macrophages at an anti-inflammatory state by a number of mechanisms that include increasing expression of the transcription factor IRAK-M (Nguyen, et al., 2012), global effects on macrophage proteome composition enriched in anti-inflammatory pathways (Phelps, et al., 2013, Phelps, et al., 2011), scavenging of pro-inflammatory mediators (Minutti, et al., 2016, Francisco, et al., 2020), suppression of NFKB activation (Younis, et al., 2020, Moulakakis, et al., 2016, Moulakakis and Stamme, 2009, Wu, et al., 2004), and modulating trafficking of innate receptors (Henning, et al., 2008, Gil, et al., 2009).

SP-A modulates the optimal relative expression of the long and short isoforms of the SP-A receptor, SP-R210 L and SP-R210s, on alveolar macrophages (Nguyen, et al., 2012, Yang, et al., 2015). SP-R210 tailors SP-A-mediated phagocytosis of SP-A opsonized pathogens and pathogen-dependent inflammatory responses by macrophages (Weikert, et al., 2000, Weikert, et al., 1997, Minutti, et al., 2017). These isoforms are encoded by alternatively spliced mRNAs of the Myo18A gene (Mori, et al., 2003, Yang, et al., 2005, Szeliga, et al., 2005), which generate tissue and cell-type specific isoforms on the cell surface and subcellular organelles (Mori, et al., 2003, Yang, et al., 2005, Szeliga, et al., 2005, Taft and Latham, 2020, Lee, et al., 2014, Ng, et al., 2013, Horsthemke, et al., 2019, Cross, et al., 2004). MYO18A isoforms have so far been classified into three broad groups, MYO18A $\alpha$, MYO18A $\beta$, and MYO18A $\gamma$, which are functionally diverse, catalytically inactive members of the myosin superfamily. SP-R210 L (aka CD245 $\alpha$ ) and SP-R210s (aka CD245 $\beta$ ) are members of the MYO18A $\alpha$ and MYO18A $\beta$ groups on the surface of macrophages and other immune cells (Yang, et al., 2005, De Masson, et al., 2016, Samten, et al., 2008), respectively. SP-R2120 L is induced during terminal macrophage 
different relative abundance in myelomonocytic lineage cells (Mori, et al., 2003, Cross, et al., 2004,

106

107

108

109

110

111

112

113

114

115

116

117

118

119

120

121

122

123

124

125

126

127

128

129

130

131

132

133

134

135 Samten, et al., 2008, Chroneos and Shepherd, 1995), although the role of each isoform and impact of SP-R210 isoform stoichiometry in macrophage development and function is not understood at the molecular, cellular levels, and organismal levels. Bone marrow-derived macrophages, monocytes, and immature myelomonocytic cells only express SP-R210s, whereas peritoneal and alveolar macrophages express both isoforms (Yang, et al., 2005, Cross, et al., 2004, Samten, et al., 2008). Previous studies demonstrated that SP-R210 regulates extrinsic ligand-dependent and intrinsic ligand-independent macrophage functions (Yang, et al., 2015, Weikert, et al., 2000, Weikert, et al., 1997, Minutti, et al., 2017, Mori, et al., 2003, Yang, et al., 2005, Cross, et al., 2004, Samten, et al., 2008, Jean Beltran, et al., 2016, Sever-Chroneos, et al., 2011, Borron, et al., 1998, Chroneos, et al., 1996, Lopez-Sanchez, et al., 2010). Ligand-dependent functions include SP-A-mediated bacterial phagocytosis coupled to production of reactive nitrogen species, secretion of TNF $\alpha$ and increased macrophage responsiveness to IFN $\gamma$ and IL-4. These functions facilitate killing and eradication of bacterial and parasitic pathogens by alveolar macrophages (Weikert, et al., 2000, Weikert, et al., 1997, Minutti, et al., 2017, Sever-Chroneos, et al., 2011, Stamme, et al., 2000). In the context of an immune memory response, however, the interaction of SP-A with SP-R210 may limit excessive activation of immune system-mediated inflammation (Samten, et al., 2008, Borron, et al., 1998). SP-R210 may exacerbate injurious inflammation by peritoneal macrophages in the presence of other ligands such as C1q (Minutti, et al., 2017), which is more abundant systemically, and innate immune cell cytotoxicity by SP-A or other ligands in different tissues (De Masson, et al., 2016).

Studies in SP-R210L-deficient macrophages revealed that depletion of the L isoform resulted in broad baseline alterations in expression, trafficking and cell-surface localization of innate receptors, and hyper-responsiveness to inflammatory stimuli (Yang, et al., 2015), suggesting global effects on macrophage phenotype and function. However, the role that SP-R210 isoforms play in macrophage function are not well-defined. Therefore, we asked whether differences in SP-R210 isoform expression patterns shape the basal macrophage phenotype and responses to infection at genomic, transcriptomic, and epigenomic levels. We found that alteration of SP-R210 isoform expression resulted in distinct gene expression patterns that reflected changes in epigenetic remodeling and chromatin accessibility in SP-R210L-depleted macrophages. Additionally, using influenza as a model of infection, our findings support the notion that SP-R210 isoforms coordinate nuclear responses to infection in macrophages. 


\section{Materials and Methods}

\section{$138 \quad 3.1 \quad$ Cell lines and Cell Culture}

139 SP-R210L-deficient RAW 264.7 macrophages (SP-R210L(DN)) were generated and characterized as 140 described previously by stable transfection of a pTriex-2 vector expressing the carboxy-terminal 141 domain of SP-R210 (SP-R210_(DN)) cells (Yang, et al., 2015, Yang, et al., 2005, Sever-Chroneos, et al., 142 2011). Most experiments utilized the SP-R210 (DN) clone DN2 (Yang, et al., 2015, Yang, et al., 2005, 143 Sever-Chroneos, et al., 2011) unless otherwise noted in Figure legend. Control cells were transfected 144 with empty vector. The deletion of both SP-R210 isoforms was achieved using CRISPR/Cas9. Guide 145 RNA sequences targeting exons 5, 6, 12, and 14 were designed using crispr.mit.edu and gRNA 146 oligonucleotides were ligated into the LRG hU6-sgRNA- EFS-GFP-P2A vector. RAW 264.7 macrophages 147 were transduced with a Cas9 containing lentivirus and selected using blasticidin to generate a stable 148 Cas9 expressing cell line. Stable Cas9 RAW264.7 cells were transfected with a pooled library of ligated 149 gRNA vectors. Transfected GFP+ cells were isolated by flow activated cell sorting into 96-well plates 150 to culture individual clones. SP-R210-deficient clones lacking both isoforms, designated, SP-R210(KO), were identified by Western blot analysis following sorting (Supplemental Figure 1), and a single clone

152 retaining deletion of both isoforms after subculture was selected for further studies. Cells were 153 maintained in DMEM culture media (DMEM with $4.5 \mathrm{~g} / \mathrm{L}$ glucose, L-glutamine, and sodium pyruvate

154 supplemented with 10\% heat-inactivated fetal bovine serum (FBS) and 1\% penicillin/streptomycin) at $15537^{\circ} \mathrm{C}$ and $5 \% \mathrm{CO}_{2}$ in $10-\mathrm{cm}$ dishes. Cells were sub-cultured in $10-\mathrm{cm}$ dishes $\times 5$ at a density of $1 \times 10^{7}$ 156 cells/dish for ChIP-seq experiments, sub-cultured in 6-well plates at a density of $1 \times 10^{6}$ cells/well for 157 RNA isolations (subjected to RNA-seq experiments), or 24 -well plates at $2 \times 10^{5}$ cells/well for flow 158 cytometry and other assays.

\subsection{Virus Preparation}

160 The mouse adapted influenza virus strain A/Puerto Rico/8/34 (PR8) influenza was propagated in the 161 allantoic fluid of embryonated chicken eggs (Sever-Chroneos, et al., 2011). Briefly, $10^{5}$ fluorescent 162 focus units (FFC) in PBS with 1\% Penicillin/Streptomycin/Fungizone was injected into the amniotic sac 163 of 10 day old embryonated chicken eggs. Infected eggs were incubated at $37^{\circ} \mathrm{C}$ for 56 hours. Eggs 
164 were then removed and placed at $4{ }^{\circ} \mathrm{C}$ for 12 hours. The allantoic fluid was collected and spun down

165 at $131,000 \mathrm{~g}$ for 40 minutes at $4^{\circ} \mathrm{C}$. The virus pellet was reconstituted in PBS and layered over a $30 \% / 35 \% / 50 \% / 60 \%$ sucrose gradient and spun at 168,000g for 1 hour and 15 minutes and the virus containing layer between $50 \%$ and $35 \%$ was collected and dialyzed against PBS at $4{ }^{\circ} \mathrm{C}$ overnight. The viral titer was determined by fluorescent plaque assays using Madine-Darby Canine Kidney (MDCK) epithelial cells (ATCC Cat \#CRL-2936) were plated in 96 well plates at a density of $3 \times 10^{4}$ serial dilutions of purified and dialyzed virus was overlayed on the cells. Cells were incubated at $37^{\circ} \mathrm{C}$ with virus for 2 hours, at which point virus-containing media was replaced with virus-free media and cells were

172 incubated for another 6 hours. Cells were then fixed with acetone, and stained with an Influenza A 173 NP antibody (Sigma Aldrich Cat\#MAB8251, 1:100 in PBS) for 30 minutes at $4^{\circ} \mathrm{C}$ and subsequently 174 labeled with Rhodamine conjugated anti-mouse IgG (Jackson ImmunoResearch, Cat\#115-026-062, 175 1:100 in PBS). Fluorescently labeled nuclei were counted using a Nikon Eclipse TE2000-U at 20x 176 magnification.

\subsection{Influenza Infection and Assessment of Infection}

178 Cells plated for infection were seeded at a density of $1 \times 10^{7}$ (ChIP-seq) or 2E5 per well for 12 hours 179 prior to infection. Cells were washed with PBS twice and PR8 virus was added at MOI 1 (ChIP-seq) or MOI 4 (cytokine elaboration studies, influenza infection studies) in infection media (1:1 ratio DMEM w/o serum to PBS) as determined by cell seeding density. Cells with infection media were incubated at $37^{\circ} \mathrm{C}$ for two hours. Infection media were removed and replaced with DMEM culture media. Infection was allowed to progress for another 10 hours or until the desired incubation time was reached. Influenza infection was assessed via viral protein production by western blot (methods outlined in 2.4), viral NP qPCR, and viral NP imaging. Supernatant and cell pellets from infected samples were collected 12 hours post infection. qPCR was performed in accordance to Fino et al (Fino, et al., 2017). RNA was prepared using the RNA-bee (Tel-Test, Inc. Cat \#CS-501B) protocol for cell supernatant and cell pellet. cDNA was synthesized with the High Capacity cDNA Reverse Transcription Kit (Invitrogen Cat\#4368814) using the IAV MP primer 5' TCT AAC CGA GGT CGA AAC GTA 3' for IAV following the manufacturer's protocol. The cDNA was diluted five-fold prior and PCR amplified using

191 the TaqMan Fast Universal PCR Master Mix (ThermoFisher Cat\#4305719). The PR8 M1 gene was amplified using the following primers: sense: 5'-AAG ACC AAT CCT GTC ACC TCTG A-3' and antisense: 
194 TTT GTG TTC ACG CTC ACC GT/36-TAMSp/-3'. Immunofluorescence of IAV-infected cells was 195 performed on PR8 infected cells PR8 at MOI10 after 15 and 30 minutes. Infected cells were fixed using $1963.7 \%$ formaldehyde for 25 minutes. Fixed cells were blocked with 10\% donkey serum and 3\% BSA in 197 0.2\% Tween 20 in PBS. Blocked cells were probed using Rab5 (Cell Signaling Technology Cat\#3547S, 198 1:200) and NP (BioRad Cat\#MCA400, 1:1000) overnight at $4^{\circ} \mathrm{C}$, and labeled using AF488 conjugated 199 anti-mouse IgG (Jackson ImmunoResearch Cat\#715-545-150, 1:500) and AF594 conjugated anti200 rabbit IgG (Jackson ImmunoResearch Cat\#711-585-152, 1:500) for 2 hours at room temperature. Cells were acquired using Nikon Eclipse Ti confocal microscope and Nikon Elements 4.30 .01 software.

\subsection{Western blot analysis}

203 Samples were harvested using 0.25\% Trypsin-EDTA (Corning Cat\#25-053-Cl); lifted cells were 204 centrifuged at 15,000g for 5 minutes at $4{ }^{\circ} \mathrm{C}$ (Eppendorf 5430R). Cell pellets were placed at $-20^{\circ} \mathrm{C}$ 205 overnight with $60 \mu \mathrm{L}$ SDS Lysis buffer (1\% SDS, 50mM Tris-HCL pH 8.1, 10mM EDTA pH 8.0) with 1x 206 Protease/Phosphatase Inhibitor Cocktail (Cell Signaling Cat\#5872S). Samples were thawed and 207 sonicated at $50 \%$ A for 10 seconds in 2 second ON/OFF intervals. Sonicated samples were centrifuged 208 at $15,000 \mathrm{~g}$ for 5 minutes at $22^{\circ} \mathrm{C}$. Supernatant was collected; $4 x$ LDS sample buffer (Invitrogen 209 Cat\#NP007) was added to a final concentration of $1 x$.

210 For gel electrophoresis, samples were diluted to $1 \mathrm{X}$ SDS-PAGE sample buffer, boiled at $90^{\circ} \mathrm{C}$ for 2 211 minutes, and centrifuged for 2 minutes at 21,000g. Equal volumes of protein were via in 4-12\% Bis-

212 Tris gels (Invitrogen, Cat\#NP0321BOX, NP0349BOX) for reducing gels and 4-12\% Bis0Tris NativePAGE 213 gels (Invitrogen, Cat \#BN1002BOX) for native, nonreducing gels and transferred using eBlot L1 214 Transfer system (GenScript). Blots were blocked in 5\% Bovine Serum Albumin (BSA) in 0.1\% Tween 21520 in Tris-buffered saline (0.1\% TBST). Blots were probed at $4^{\circ} \mathrm{C}$ overnight with MYO18A (Proteintech 216 Cat\#14611-1-AP, 1:1000), p-IRF3 Ser396 (Cell Signaling Technology Cat\#29047, 1:1000), IRF3 (Cell

217 Signaling Technology Cat\#4302, 1:1000), p-IRF7 Ser437 (Cell Signaling Technology Cat\#24129, 218 1:1000) , IRF7 (Aviva Systems Biology Cat\#OAAN00009), p-p65 Ser276 (Thermo Fisher Cat\#PA5-37718, 219 1:1000), p-p65 Ser536 (Cell Signaling Technology Cat\#3033, 1:1000), NFkB p65 (Cell Signaling 220 Technology Cat\#8242, 1:1000), STING (Cell Signaling Technology Cat\#50494, 1:1000), or GAPDH 221 (Thermo Fisher Cat\#PA1-16777, 1:5000) in 0.1\% BSA in 0.1\% TBST and subsequently imaged using 222 HRP-conjugated anti-rabbit antibodies (Bio-Rad Cat\#172-1019, 1:10000) and Western Lightning Plus223 ECL (PerkinElmer Cat\#El103001EA) on a BioRad Chemidoc imager. Images were adjusted and band 
224 densitometry was determined using ImageLab 5.2.1. PU.1 (Invitrogen Cat \#MA5-15064, 1:500-1000),

225 NS1 (Invitrogen Cat \#PIPA532243, 1:1000), NP (BioRad Cat\#MCA400, 1:1000), and anti- $\beta$-actin (Sigma

226 Aldrich Cat \#A2228-100UL, 1:20000) blots were incubated with the relevant primary antibodies at

$2274^{\circ} \mathrm{C}$ overnight and imaged using with IRDye 680RD anti-Mouse IgG (LI-COR Cat\#926-68070, 1:15000)

228 and IRDye 800 CW anti-Rabbit IgG (LI-COR Cat\#926-32211, 1:10000). Blots were imaged using LI-COR

229 Odyssey CLx and Image Studio 4.0. Band densitometry was acquired and images were adjusted using

$230 \quad$ Image Studio Lite 5.2.5.

\section{$231 \quad 3.5 \quad$ Cytokine analysis}

232 Cytokines were assessed from clarified supernatant using R\&D Quantikine ELISA kits for TNF $\alpha$ (R\&D 233 Systems, Cat\#MTA00B) and DuoSet ELISA kits for IFN $\beta$ (R\&D Systems, Cat\#DY8234-05). $500 \mu L$ of supernatant was collected from cell culture experiments, and spun at 15,000g for 10 minutes to remove debris. Clarified supernatants were aliquoted and frozen before utilizing in ELISA experiments. ELISAs were performed following manufacture protocol without diluting supernatant samples.

\subsection{Flow cytometry}

Control, SP-R210L(DN), and SP-R210(KO) RAW 264.7 cells were detached using non-enzymatic cell dissociation medium (Sigma-Aldrich Cat\#C1544-100ML) and washed in PBS containing 2\% fetal bovine serum (FBS). Cells were washed by centrifugation and discarding of supernatant, then blocked with mouse Fc block (BD Biosciences Cat\#553142) in PBS at a concentration of $12.5 \mu \mathrm{g} / \mathrm{mL}$ and $2 \%$ FBS for 10 minutes at room temperature. After blocking, cells were washed and stained with recommended concentrations of monoclonal antibodies for $30 \mathrm{~min}$ at $4{ }^{\circ} \mathrm{C}$. Staining was divided into two panels; Cells were washed and placed into HBSS with $2 \%$ FBS and $0.02 \%$ sodium azide until assessment via BD LSRII flow cytometer. A minimum 30,000 events were collected and data were analyzed via FlowJo 9.8.8. Antibodies used are as follows; CD204 (Bio-Rad Cat\#MCA1322A488T, 2F8);

247 MHC II (eBioscience Cat\#86-5321-42, M5/114.15.2); CD11b (BioLegend Cat\#101242, M1/70); Ly6C 248 (BD Cat\#561237, AL-21); TLR2 (eBioscience Cat\#12-9021-82, 6C2); F4/80 (eBioscience Cat\#25-4801-

249 82, BM8); CD36 (BD Horizon Cat\#585933, CRF D-2712); SIRP $\alpha$ (BD Optibuild Cat\#742205, P84); CD11C 250 (eBioscience Cat\#17-0114-82, N418); TLR4 (eBioscience Cat\#12-9041-80, UT41); CD14 (eBioscience 251 Cat\#25-0141-82, SA2-8); SiglecF (BD Horizon Cat\#562681, E50-2440) 


\subsection{RNA isolation}

253 RNA was isolated from $1 \times 10^{6}$ cells per sample using the RNA-Bee ${ }^{\mathrm{TM}}$ (Tel-Test, Inc. Cat\#CS-501B) 254 protocol as described in detail previously (Halstead, et al., 2018). Briefly, plated cells were washed with PBS and $0.5 \mathrm{~mL}$ of RNA-Bee Isolation Reagent was added to the cells, lysed with repeated pipetting, and transferred to a microcentrifuge tube followed by the addition of $0.1 \mathrm{~mL}$ of chloroform was added, mixed by shaking for $15-30$ seconds. and centrifuged at $12,000 \mathrm{~g}$ for 15 minutes at $4^{\circ} \mathrm{C}$. The aqueous phase was retained and mixed with $0.5 \mathrm{~mL}$ ice-cold isopropanol and placed at $-20^{\circ} \mathrm{C}$ for 3 hours. Samples were then centrifuged at $12,000 \mathrm{~g}$ for 15 minutes at $4{ }^{\circ} \mathrm{C}$ and supernatant was discarded. Precipitated RNA was washed with $1 \mathrm{~mL}$ ice-cold 75\% ethanol twice, and then allowed to air dry for $15-30$ minutes at $4^{\circ} \mathrm{C}$. RNA was dissolved in $25 \mu \mathrm{L}$ RNAse, DNAse-free deionized water. RNA concentration and purity were determined by NanoDrop (Thermo Scientific) to confirm an A260:A280 ratio above 1.9. RNA integration number (RIN) was measured using BioAnalyzer (Agilent Technologies) RNA 6000 Nano Kit.

\subsection{RNA sequencing and analysis}

The cDNA libraries were prepared using the NEXTflex ${ }^{\mathrm{TM}}$ Illumina Rapid Directional RNA-Seq Library Prep Kit (BioO Scientific) as detailed previously (Halstead, et al., 2018). The libraries were pooled and loaded onto an S1 flow cell on an Illumina NovaSeq 6000 (Illumina) and run for 2X50 cycles at a depth of 25 million reads per sample. De-multiplexed and adapter-trimmed sequencing reads were aligned to the mm10 reference genome using hisat2 (v2.1.0) (Kim, et al., 2015). Abundance for each gene was obtained using featureCounts function available in Rsubread R package (Liao, et al., 2019). The raw count data from 3 independent replicates were analyzed using DESeq2 to obtain differentially expressed genes in uninfected samples, while 2 independent replicates were used for infected experiments (Love, et al., 2014). DESeq2 results were filtered for differentially expressed genes with a p-value of less than 0.05 . MGI annotations of immune associated genes were obtained from the gene ontology term 0002376 (http://www.informatics.jax.org/). Differentially expressed immune genes were obtained by filtering the DESeq 2 results with $\mathrm{p}$-value $<0.05$ against the $\mathrm{MGI}$ database of immune-associated genes. Genes with p-value less than 0.05 were mapped to KEGG pathways using fgsea (Fast Gene Set Enrichment Analysis) package (Kanehisa and Goto, 2000, Korotkevich, et al., 
281 pathway analysis of the most highly expressed gene transcripts $q<0.2$ as measured by Fisher's exact 282 test.

283

284

\subsection{Chromatin Immunoprecipitation}

Five plates each of SP-R210 L(DN) and WT cells were cultured at a density of $1 \times 10^{7}$ for a total of $5 \times$ $10^{7}$ cells. Cells were removed from the plates and cross-linked for $10 \mathrm{~min}$ with $1 \%$ formaldehyde in the growth medium. Chromatin was fragmented using the Bioruptor sonicator (Diagenode) for 30 min (30s pulses, 30s pauses in between for $10 \mathrm{~min}$, run 3 times) to produce fragments $\sim 400 \mathrm{nt}$ in size. ChIP assays were performed as reported by Wang et al. (Wang, et al., 2016). Briefly, $25 \mu \mathrm{L}$ of sheared DNA was aliquoted to run as input DNA. anti-PU.1 antibody (50 $\mu$ L; Invitrogen Cat \#MA5-15064, E.388.3), anti-H3K4me3 (40 $\mu \mathrm{L}$; Sigma Aldrich Cat\#07-449), anti-H3K9me3 (40 $\mu \mathrm{L} ;$ Abcam Cat\#ab8898), or anti-H3K27me3 (40 $\mu \mathrm{L}$; Abcam Cat\#ab8580) was incubated with $100 \mu \mathrm{L}$ of washed Goat-anti-rabbit IgG Dynabeads (Invitrogen Cat\#11203D) at $4{ }^{\circ} \mathrm{C}$ overnight in BSA blocking solution (0.5\% BSA in PBS). PU.1 antibody-coated Dynabeads (100 $\mu \mathrm{L})$ were incubated with $500 \mu \mathrm{L}$ chromatin in TE buffer (with $0.1 \%$ deoxycholate, $1 \%$ Triton $\mathrm{X}-100$ ) overnight at $4^{\circ} \mathrm{C}$ on rotator (Barnstead Labquake Model 4152110). Protein/DNA complexes were washed with RIPA buffer and captured with a Magnetic Particle Concentrator (Invitrogen). DNA-protein crosslink was reversed via incubation at $65^{\circ} \mathrm{C}$ overnight. Samples were treated with $1 \mathrm{mg} / \mathrm{mL}$ proteinase $\mathrm{K}$ for 2 hours at $37^{\circ}$. DNA was extracted using phenol and chloroform extraction and precipitated using $100 \%$ EtOH. The dried DNA pellet was reconstituted in $50 \mu \mathrm{L} \mathrm{H} \mathrm{H}_{2} \mathrm{O}$ treated with $330 \mu \mathrm{g} / \mathrm{mL}$ of RNase A for 2 hours at $37^{\circ} \mathrm{C}$ and then recovered using the QIAquick PCR Purification kit (QIAGEN Cat\#28104). DNA concentration was determined by Qubit (Thermofisher).

\subsection{ChIP sequencing and analysis}

Libraries of ChIP-derived DNA were sequenced via Illumina NGS. Sequences were aligned to the mm10 genome using the mem function of the bwa package. Peaks were identified from the bed files using the callpeaks function of MACS2 (v2.1.0). Peak annotation and identification of overlapping peaks was done via ChIPpeakAnno (v3.14) using the UCSC mm10 annotated genome (Zhu, et al., 2010). Concordant peaks between the two replicates were selected for further analysis using overlappingPeaks function set at a maxgap=50. Genomic distribution of peaks and pathway analysis 
was performed using ChIPseeker (v1.16), ReactomePA (v1.24), and clusterProfiler (Yu, et al., 2015, Yu and $\mathrm{He}, 2016)$.

\subsection{Statistical Analysis}

312 Statistical comparison of data was performed using GraphPad Prism 7.0d software (San Diego, CA).

313 2-way ANOVA with paired samples and unpaired comparisons via t-test corrected by the Holm-Sidak

314 method were used to assess statistical differences. $p$-values $<0.05$ were considered significant.

3164 Results

\subsection{SP-R210 isoform deficient macrophages exhibit basal immune activation pathways}

Previous work has shown that knockdown of the longer SP-R210 L isoform (SP-R210L(DN)) alters cell-surface expression of multiple innate receptor and macrophage differentiation markers (Yang, et al., 2015) (Supplemental Figure 1b). We assessed the impact of SP-R210 isoform deficiency on the basal transcriptome to better understand the phenotypic and functional differences of SP-R210 deficient macrophages. Deseq2 was used on RNA-seq from 3 independent replicates of WT and SPR210 (DN) cells to identify differentially expressed genes. This investigation revealed significant differences in the basal transcriptome profile between WT and SP-R210L(DN). Selective deletion of the SP-R210 isoform resulted in upregulation of 1273 genes ( $p<0.05)$, with Fads2, Igf1, Runx3, Cxcl10, Ly86, Ifi44, Ifi44l among the top 20 genes with the largest expression differences (Figure 1a, Supplementary Table 1). Furthermore, upregulated genes such as Hhex and $/ / 2 \mathrm{rg}$ were identified by their extremely low $p$-value. Conversely, knockdown of the $L$ isoform resulted in downregulation of 1652 genes, with Dlg5, Maged1, Bco1, Tmem54 Col5a1, and Kdm5d among the top 20 most downregulated genes (Figure 1a, Supplemental Table 1). Other downregulated genes that were identified by noticeably low p-values included Cc16, Lyz1, Myo6, Stard10, and Zcchc24. Immune associated genes were then identified within the differentially expressed genes by filtering by the gene ontology term GO: 0002376. This filtering identified most of the top upregulated immune associated genes in SP-R210 (DN) cells, such as Tnfsf8, Ifi44, Ifi44I, Ly86, Runx3, Igf1 (Figure 1a (red downregulated in SP-R210 (DN) cells compared to WT cells, respectively. 
Differentially expressed genes were then analyzed for enrichment in KEGG signaling/metabolism pathways using the fgsea $\mathrm{R}$ package. This analysis revealed induction of cytosolic innate recognition pathways for bacteria, RNA and DNA viruses (NOD, RIG-I, and STING, respectively) in SP-R210 L(DN) cells as well as cell-surface and endosomal toll-like receptors (Figure 1c,

341 Supplemental Figure 2). Furthermore, several innate sensing pathways (i.e. TLR sensing, NOD sensing)

342 were upregulated in SP-R210 (DN) cells, which appears to be skewed towards an anti-viral response 343 due to upregulation of cytosolic DNA sensing pathways and RIG-I. Accordingly, the disease associated pathways most upregulated at baseline in SP-R210 (DN) cells were anti-viral response pathways, including responses to Hepatitis C, Epstein-Barr Virus and Influenza A (Figure 1d).

To address the impact of both isoforms, a SP-R210(KO) RAW264.7 macrophage line was generated by CRISPR-Cas9-mediated deletion of both isoforms and expansion of a single clone selected by fluorescence-activated cell sorting (FACS) and deletion confirmed by western blot (Supplemental Figure 1a). Phenotypic analysis by flow cytometry discerned three phenotypes of

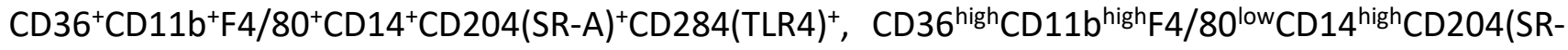

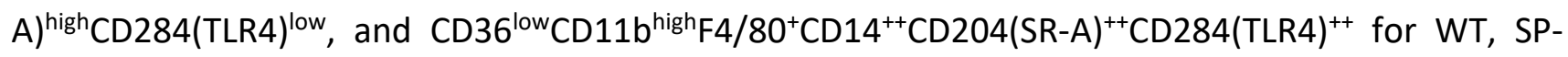
R210 (DN), and SP-R210(KO) cells (Supplemental Figure 1b), respectively. TLR2, SIRP $\alpha$ CD11c, Ly6C, and MHC-II were also highly induced in SP-R210 L(DN) cells while only moderately elevated in SPR210(KO) cells compared to WT (Supplemental Figure 1b).

Comparative analysis of RNAseq data revealed that disruption of $L$ and both $L$ and $S$ isoforms results in widespread transcriptome adaptation affecting both immune and nonimmune genes. 804 genes were upregulated and 778 downregulated in SP-R210(KO) cells compared to WT. Tnfsf4, Plch1, Amer3, and Cxcl10 were among the top 20 upregulated genes in the SP-R210(KO) cells, while Maged1, Zfhx4, Cldn11, and Csf1 were among the 20 most downregulated genes (Supplemental Figure 1c, Supplemental Table 1). Compared to SP-R210 (DN) cells, 1936 genes were upregulated while 1525 genes were downregulated in SP-R210(KO)cells compared to SP-R210 (DN) cells. Upregulated genes included Bco1, Tmem54, Ifi27/2b, and Kdm5d, while Ly86, Igf1, Fads2, Runx3, Ifi44, Csf1, Ifi44I, and CD86 were among the top 20 downregulated genes (Supplemental Figure 1d, Supplemental Table 1). Ly86, Ifi44, Ifi44I, Runx3, and Fads2 were all among the top 20 genes that were downregulated in both WT and SP-R210(KO) cells compared to SP-R210 (DN) cells. Furthermore, 224 transcripts common to both SP-R210 (DN) and SP-R210(KO) were downregulated while 596 genes were upregulated in both cell types compared to WT cells (Supplemental Figure 1g) and of these, 171 
368

369

370

371

372

373

374

375

376

377

378

379

380

381

382

383

384

385

386

387

388

389

390

391

392

393

394

395

396

397

upregulated and 101 downregulated transcripts are from immune-associated genes. Among the top 20 upregulated genes in SP-R210(KO) cells, only Tnfsf4, Itga2, Ifi27/2b, and Cxcl10 were immuneassociated compared to WT cells (Supplemental Figure 1c, red dots). Tnsfsf4 and Ifi27/2b remained elevated in SP-R210(KO) cells to SP-R210 (DN) cells (Supplemental Figure 1d, red dots). KEGG pathway analysis showed that only RIG-I and NOD-like receptor signaling pathways remained elevated SPR210(KO) compared to WT cells-(Supplemental Figure 1e, 1f), whereas nucleic acid sensing pathways were not affected. Taken together, these findings indicate basal macrophage activation readiness at the transcriptional level depends on differential expression of SP-R210 isoforms.

\subsection{Depletion of SP-R210L alters genome wide binding of PU.1}

To further understand the impact of $L$ depletion, chromatin immunoprecipitation and sequencing (ChIP-seq) was used to determine the genome-wide distribution of PU.1 binding in WT and SP-R210 (DN) cells. PU.1, a pioneer transcription factor, plays a key role in macrophage function and lineage through its interaction with a constellation of transcription factors at distal gene enhancer and proximal promoter elements, allowing it to prime expression of various macrophage and immune associated genes (Shibata, et al., 2001, Glass and Natoli, 2016, Hoogenkamp, et al., 2007, Imperato, et al., 2015, Petrovick, et al., 1998, Schmidt, et al., 2016, Berclaz, et al., 2007). ChIP-seq was performed on two independent samples for each cell type; concordant peaks were identified between both replicates and were used for further analysis. Comparative analysis of ChIP-seq peaks showed that the number of PU.1 binding sites increased in SP-R210L(DN) cells compared to WT (Figure 2a). Furthermore, ChIPseeker analysis revealed that SP-R210L(DN) cells had a greater distribution of PU.1 binding in introns than in WT cells (34.64 \% vs 33.57\%, respectively (Figure $2 \mathrm{~b}$ ). Conversely, binding in promoter regions and regions downstream of gene transcriptional start sites decreased in SPR210 (DN) compared to WT cells (24.94 vs 26.11\%, respectively) (Figure 2b). Differences in PU.1 binding were not due to differences in PU.1 expression levels, as demonstrated by Western blot analysis (Supplemental Figure 2a, 2b). These results indicate that knockdown of SP-R210 shifts the distribution of PU.1 binding sites between intergenic and proximal gene promoter sites.

The PU.1 peaks were annotated using ChIPseeker, to associate the peaks to specific genes. Of the 1320 peaks unique to WT cells, 260 of the peaks were associated with transcripts downregulated in SP-R210 (DN) cells, while 49 peaks were associated with upregulated transcripts in SP-R210L(DN) cells. Of the 5365 peaks unique to SP-R210 (DN) cells, 573 were associated with upregulated 
transcripts in the knockdown cells, while 437 were associated with downregulated transcripts in the knockdown cells (Supplemental Table 2a, Supplemental Figure 3). Additionally, of the 1273 upregulated genes in SP-R210 L(DN) cells, 363 had PU.1 peaks that were found exclusively in SPR210 (DN) cells, with 44 genes having PU.1 peaks exclusive to WT cells. Within the 1652 downregulated genes, 226 genes had PU.1 peaks unique to WT cells, while 308 genes had PU.1 peaks unique to the SP-R210 L(DN) cells (Figure 2c). Of note, upregulated SP-R210 L(DN) genes that had PU.1 peaks unique to these cells include several immune associated genes, such as Ly86, Csf3r, Pde8a, and

Igf1, as well as epigenetic regulators such as Hdac9 (Supplemental Table 2a). On the other hand, downregulated SP-R210 (DN) genes that associated with unique PU.1 peaks in the knockdown cells include genes nvolved in signaling, such as Marcks, Rgs9, Fgr and Plekha6 (Supplemental Table 2b).

We then used the ReactomePA package to map gene regions immunoprecipitated by PU.1 to Reactome pathways and clusterProfiler to determine pathway clustering. This analysis showed enrichment in pathways involved in macrophage function in both WT and SP-R210L(DN) cells. Pathways regulating Fc gamma receptor dependent phagocytosis, genes regulating actin dynamics for phagocytic cup formation, as well as other immune associated pathways, such as IL-3,5 and GMCSF signaling, and CD28 co-stimulation pathways (Supplemental Figure 4). SP-R210 (DN) cells, however, showed an increased representation of genes involved in TLR pathways (Figure $2 d$, Supplemental Figure 5), consistent with the RNA-seq data showing differential expression of transcripts associated with TLR signaling (Figure 1b). Other pathways include genes involved in TNF,

417 interferon, Fc epsilon receptor, and NLR signaling pathways. Cyclin D associated events in G1, and 418 transcriptional regulation of TP53 were also differentially bound by PU.1 binding in SP-R210L(DN) cells 419 (Supplemental Figure 4).

\subsection{Differential distribution of histone methylation marks in WT and SP-R210L(DN) cells}

Previous studies reported that PU.1 binding is influenced by histone $3(\mathrm{H} 3)$ methylation (Cheng, et al., 2013, Burda, et al., 2016, Tagore, et al., 2015). Methylation marks on lysine residues of histone

$4233(\mathrm{H} 3)$ are associated with certain chromatin conformations; H3K4me3 with open chromatin and transcriptional activity, and H3K9me3 and H3K27me3 are typically associated with closed chromatin and thus transcriptional suppression. Profiling of by ChIP-seq showed increased H3K4 trimethylation (H3K4me3) in SP-R210L(DN) cells compared to WT cells (Figures 3a, 3b). Conversely, methylation 
428 trimethylation (H3K27me3), were decreased in SP-R210 (DN) cells compared to WT cells (Figures 3c, $4293 \mathrm{~d}, 3 \mathrm{e}$, and $3 \mathrm{f})$. The distribution of these methylation marks was also altered around specific genomic 430 features in SP-R210 L(DN) cells with decreased distribution of H3K4me3 marks in promoter regions, 431 whereas H3K4me3 was higher in introns and intergenic regions (Figure $3 \mathrm{~b}$ ). The H3K4me3 432 methylation pattern overlapped with 23.5\% and 34.9\% of PU.1 binding sites representing 1911 regions in WT cells and 10413 in SP-R210 (DN) cells (Figure 3g, 3h), respectively.

Plotting of bedgraphs on the UCSC browser was used to examine the relationship between PU.1 binding and histone methylation pattern for TLR genes, since TLR response pathways were differentially affected in SP-R210L(DN) cells. Concordant peaks for both PU.1 and H3K4me3 in the promoter regions of $T / r 3,5,6$, and 9 were broad and narrow in WT and SP-R210 (DN) cells, respectively. However, there were additional and/or shifted peaks for PU.1 and H3K4me3 near the transcriptional start site of T/r2, T/r5, T/r6, TIr9 and T/r13 in SP-R210L(DN) cells (red arrows, Supplemental Figure 5). Sharp PU.1 peaks near or further upstream the transcriptional start site for TIr4 and TIr7 were not different between WT and SP-R210 (DN) cells, and these peaks were not concordant to H3K4me3 (Figure 4a, Supplemental Figure 5). There were no discernible PU.1 or H3K4me3 peaks for TIr1, TIr3, TIr8, TIr11 and TIr12 (Supplemental Figures 6). Narrow PU.1 peaks at sites distal to the promoter of T/r13 were discernible only in SP-R210L(DN) regions and these peaks were concordant to H3K4me3 (Supplemental Figure 5). Validating our immunoprecipitation experiment, PU.1 binding was identified at the known enhancer binding site upstream of the PU.1 transcriptional start site in both WT and SP-R210 (DN) cells (Figure 4b). A low intensity PU.1 peak in the proximal PU.1 promoter was retained in WT but not SP-R210L(DN) cells, whereas a broad H3K4Me3 peak was present in both (Figure 4b). By comparison, chromatin peak analysis of the Csfr1 gene revealed broad and narrow PU.1 and H3K4Me3 peaks downstream of the first exon in WT and SP-R210 L(DN) cells, respectively (Supplemental Figure 5). Bedgraph analysis of the Myo18A gene encoding SP-R210 isoforms revealed two consensus PU.1 binding motifs in the reverse complement and forward strand orientations (Figure 4c). Of these, only the intronic cis site was occupied by PU.1 in both WT and SP-R210 L(DN) cells. An additional non-consensus PU.1 binding peak was present upstream in the same intron, suggesting indirect PU.1 binding at this site. Sequence analysis of these peaks revealed a canonical PU.1 binding sequence near the intronic peak, while a non-canonical PU.1 
V, 2016). A sharp H3K4Me3 peak in the promoter region had reduced intensity in SP-R210_(DN) cells (Figure 4c).

460

\subsection{IAV infection results in repression and redistribution of PU.1 binding and differential outcomes of cellular death and signaling responses in WT and SP-R210L(DN) cells}

462

PU.1 is critical for the terminal differentiation of alveolar macrophages downstream from GM-

463 CSF receptor signaling in the local microenvironment (Carey, et al., 2007). In turn, alveolar macrophages are essential for host survival from severe influenza A virus (IAV) infection (Halstead, et al., 2018, Sever-Chroneos, et al., 2011, Umstead, et al., 2020, Huang, et al., 2011). Raw264.7 cells have been extensively utilized as a surrogate in vitro model to study IAV infection in macrophages with all known IAV strains (Marvin, et al., 2017, Cline, et al., 2017). Infection of IAV in macrophages is largely abortive, whereby replication, transcription, and translation of viral genes takes place with minimal packaging and release of viral progeny (Marvin, et al., 2017, Cline, et al., 2017). Therefore, we asked whether IAV infection on alters PU.1 chromatin occupancy in WT and SP-R210L(DN) cells. IAV infection and lack of the $L$ isoform did not alter PU.1 expression WT and SP-R210L(DN) cells (Supplemental Figure 3). ChIP-seq immunoprecipitation experiments revealed that IAV infection reduced PU.1 binding by almost 40 and 65\%, respectively, compared to uninfected cells (Figure 5a, 5b). The SP-R210 L(DN) genome had 3153 fewer PU.1 peaks compared to uninfected cells, whereas the number of PU.1 peaks in SP-R210 (DN) cells decreased by 7560 compared to uninfected cells (Figure 5a). Of these, 733 and 197 PU.1 peaks were uniquely associated with infection in WT and SPR210 (DN) cells, respectively (Figure 5b). Mapping of these unique peak regions showed increased distribution of PU.1 peaks in proximal promoter regions by 7 and 3.3\%, or a 2-fold difference between infected WT and SP-R210 (DN) cells, respectively. The 2-fold increase reflected lower PU.1 distribution in intronic and distal intergenic regions in WT cells compared to lower distribution in intronic regions in SP-R210 (DN) cells (Figure 5c). PU.1 peaks in shared genomic regions mapped to mostly macrophage function and activation pathways (e.g. Fc gamma receptor dependent phagocytosis, regulation of actin dynamics for phagocytosis, clathrin-mediated endocytosis, and signaling by RHO GTPases) in both WT and SP-R210 (DN) cells (Figure 5d, Supplemental Figure 8) and these were selectively suppressed after infection of SP-R210L(DN) cells. IAV infection, however, resulted in differential increase in association of PU.1 with genes regulating apoptotic and hyaluronan metabolism pathways, whereas binding to genes associated with proinflammatory TLR pathways 
decreased in WT and SP-R210 (DN) cells, respectively (Figure 5d, Supplemental Figure 10). Accordingly, flow cytometric experiments confirmed the pro-apoptotic phenotype of WT cells and resistance to apoptosis in response to IAV infection in WT and WT and SP-R210L(DN) cells, respectively (Supplemental Figure 9a) and activation of apoptotic, cell death, and sirtuin pathways (Supplemental Figure 9b). On the other hand, phosphorylation of IRF3 and IRF7 were both enhanced by 12 and 24 hrs after IAV infection in SP-R210 (DN) cells compared to WT (Figure 6a, b), consistent with enhancement of interferon and TLR signaling pathways. IAV infection increased Furthermore, expression of TLR7 but not TLR4 (Supplemental Figure 10) in SP-R210 (DN) cells compared to WT. Analysis of NFKB p65 phosphorylation revealed basal increase in the levels of serine 276 which remained elevated after infection in SP-R210L(DN) cells (Figure 6c), whereas phosphorylation of serine 536 was differentially induced in WT cells. Given that serine 536 phosphorylation is involved in negative regulation of NFKB signaling (Pradere, et al., 2016), we assessed phosphorylation of the upstream p65 kinase p38 (Song, et al., 2006, Schmeck, et al., 2004). Accordingly, Figure 8d shows that IAV infection induced phosphorylation of p38 in WT but not SP-R210L(DN) cells (Figure 6d). This difference aligns with the decrease in PU.1 binding to genes that regulate MAPK signaling (Figure $5 \mathrm{~d}$ ).

\section{Discussion}

This study explored how SP-R210 isoforms coordinate macrophage transcriptional and epigenetic regulation of macrophage function. We report that depletion of the $L$ isoform switches macrophages to a primed state marked by heterochromatin reduction accelerating responses to inflammatory and infectious stimuli. Previous studies showed that selective disruption of SP-R210 in macrophages alters activation state coupled to changes in trafficking and expression of phenotypic markers of macrophage activation and differentiation, encompassing pattern recognition, scavenger, and adhesion receptors enhancing phagocytic function and responsiveness to inflammatory and infectious stimuli extrinsic ligand-independent functions of SP-R210 that depend on relative

512 abundance of SP-R210 isoforms (Yang, et al., 2015, Yang, et al., 2005, Sever-Chroneos, et al., 2011).

513 Here, we extend upon these findings, showing that selective disruption of the $L$ isoform results in

514 broad priming and activation of antiviral response pathways and chromatin accessibility and remodeling as demonstrated by transcriptome analysis and chromatin immunoprecipitation

516 experiments. Additionally, disruption of both isoforms appears to result in an intermediate 517 phenotype marked by normalization of most cell-surface markers examined and moderate anti-viral 
response to influenza infection compared to WT and SP-R210L(DN) cells, supporting that the $L$ and $S$

519 isoforms modulate antagonistic extremes of macrophage. inflammatory and anti-inflammatory

520 activation states in part through a signaling mechanism that modulates PU.1-dependent chromatin

521 remodeling.

522 Transcriptome data support the novel hypothesis that L-deficient macrophages undergo 523 metabolic, transcriptional, and epigenetic adaptation related to lipid and fatty acid uptake, utilization, 524 and metabolism to be addressed in future studies. Thus, it is noteworthy that expression of fatty acid 525 uptake and metabolism genes Fads2 and Igf1 mRNA, and cell-surface CD36 and SR-A proteins (Oishi, 526 et al., 2017, Koundouros and Poulogiannis, 2020, Cucchi, et al., 2019, Spadaro, et al., 2017) were 527 highly induced in uninfected SP-R210 (DN) cells. In contrast, deletion of both isoforms diminished 528 cell-surface expression of CD36. Phenotypic expression level of CD36 distinguished anti-inflammatory 529 from inflammatory macrophages in human adipose tissue based on diminished and high CD36 530 expression, respectively (Kralova Lesna, et al., 2016). It is also noteworthy that histone deacetylase 9 531 (Hdac9), a deacetylase for histones, transcription factors, and other signaling molecules, was highly 532 induced in SP-R210 (DN) cells. HDAC9 is one of several deacetylases that promote inflammatory M1 533 macrophage polarization by repressing nuclear receptors and cholesterol efflux (Cao, et al., 2014).

534 Furthermore, deacetylation of the interferon regulating kinase TBK1 by HDAC9 was shown to enhance 535 production of Type I interferon augmenting antiviral activity (Li, et al., 2016), consistent with the basal 536 anti-viral phenotype of the L-deficient macrophages. Accordingly, TBK1 and related antiviral control 537 genes were induced in SP-R210 (DN) cells after IAV infection, whereas the infection resulted in 538 apoptotic and sirtuin pathway involvement in WT cells. Sirtuins respond to cellular NAD+/NADH redox 539 balance bioavailability, thereby targeting a broad range of protein substrates that drive apoptosis, 540 DNA repair, metabolism, and inflammation in response to different cellular conditions (Zhang and 541 Sauve, 2018).

542 The global transcriptome adaptation of the L-deficient cells was accompanied by differences 543 in accessibility of the transcription factor PU.1 and chromatin remodeling as demonstrated by 544 increased genome-wide deposition of PU.1 and epigenetic histone modification. The pattern of 545 histone methylation marks is consistent with increased activation state of SP-R210L(DN) cells as 546 indicated by increased number of genes associated with H3K4me3 compared to decreases in $547 \mathrm{H} 3 \mathrm{~K} 9 \mathrm{me} 3$ and H3K27me3 associated chromatin, although in all cases there was marked redistribution 548 of these trimethylated histones from promoter to non-promoter regions. As a pioneer transcription 
549 factor, PU.1 interacts with both promoter and non-promoter regions throughout the genome in both 550 active and repressive chromatin, regulating chromatin accessibility and gene expression. PU.1 551 maintains chromatin at an open conformation to allow binding of stimulus-dependent transcription

552 factors and elicit expression of macrophage activation genes by displacing nucleosomes, whereas 553 tight control of PU.1 levels plays a critical role in the fate of hematopoietic stem cells towards myeloid 554 or lymphocytic lineages. On the other hand, chromatin structure and composition of methylated and 555 acetylated histones may limit PU.1 access in closed transcriptionally inactive chromatin after lineage 556 commitment (Glass and Natoli, 2016, Hoogenkamp, et al., 2007, Imperato, et al., 2015, Petrovick, et 557 al., 1998, Schmidt, et al., 2016, Karpurapu, et al., 2011, Liu and Ma, 2006, Rosa, et al., 2007, Celada, 558 et al., 1996, Ha, et al., 2019, Qian, et al., 2015, Rothenberg, et al., 2019, Ghisletti, et al., 2010, van Riel 559 and Rosenbauer, 2014, Leddin, et al., 2011, Rojo, et al., 2017, Schroder, et al., 2007, Lichanska, et al., 560 1999, Ross, et al., 1998, Reddy, et al., 1994). The number of PU.1 peaks in active chromatin enriched 561 in H3K4Me3 increased five-fold in L-deficient cells, indicating marked reconfiguration of chromatin of 562 the SP-R210 L(DN) cell genome from a closed to an active state, although additional DNA accessibility 563 studies are needed to validate this finding. Lack of $L$ did not have a major impact on the overall 564 fractional distribution of PU.1 between promoter and non-promoter binding sites in uninfected cells.

565 Selective analysis of PU.1 bound genes revealed sharp PU.1 peaks near transcriptional start sites in 566 SP-R210 (DN) cells compared to the broad heterogeneous PU.1 peaks, or a complete absence of

567 peaks, in WT cells at proximal intronic regions downstream from the transcriptional start site in 568 several but not all TLR genes (TIr3, 5, 6, 9, and 13). Analysis of the TATA-less Csfr1, a known PU.1 569 regulated gene that encodes the M-CSF receptor, displayed similar repositioning as seen with narrow 570 PU.1 binding peaks in the known PU.1 intronic binding sites in this gene. In contrast, the shape of the

571 PU.1 peaks in the enhancer regions -15 to $-8 \mathrm{~kb}$ upstream the PU.1 promoter (van Riel and 572 Rosenbauer, 2014, Leddin, et al., 2011) were not affected. PU.1 binding consensus motifs were 573 identified inside the first intron and upstream near the transcriptional start site on the opposite 574 strand of the Myo18A gene, although only the intronic site was occupied in a sharp PU.1 peak and 575 this was similar in both WT and SP-R210 (DN) cells. Whether this PU.1 site contributes to expression 576 for the $L$ isoform in mature macrophages but not macrophage precursors remains to be determined. 577 Therefore, downregulation of the $L$ isoform alters local positioning and complexity of intragenic PU.1 578 binding and association with promoter and intronic elements. 
In response to IAV infection, however, there was marked expulsion of PU.1 binding, depleting

580 PU.1 from genes affecting diverse regulatory processes in WT cells but predominantly macrophage

581 activation genes regulating toll-like receptor signaling in SP-R210 (DN) cells. Assessment of bound

582 PU.1 showed increased distribution of PU.1 promoter sites associated with activation of cellular death

583 pathways and metabolism in WT and SP-R210L(DN) cells. The SP-R210L(DN) cells, however, retained

584 the ability to elaborate anti-viral responses to IAV infection. These findings support the model that

585 depletion of SP-R210 results in PU.1-dependent heterochromatin reduction and basal activation of

586 SP-R210 $-\mathrm{S}+$ macrophages priming macrophage activation through differential regulation of p38 and

587 NFKB pathways and activation of IRF3/7 signaling in response to influenza infection.

\section{Conclusion}

590

591

This study explored how SP-R210 isoforms coordinate macrophage transcriptional and epigenetic regulation of macrophage function. We report that depletion of the $L$ isoform switches macrophages to a primed state marked by associated heterochromatin reduction that was accompanied by redistribution and expansion of PU.1 chromatin occupancy. This chromatin remodeling may accelerate responses to inflammatory and infectious stimuli. To this end, the mechanisms that elicit PU.1 redistribution and heterochromatin reduction in macrophages and other immune cells are only partly understood (Tagore, et al., 2015, Minderjahn, et al., 2020, McAndrew, et al., 2016). On the other hand, decline in expression of the $L$ isoform alters SP-A binding from linear non-cooperative to binding with positive cooperative behavior (Supplemental Figure 11a and b) in WT and SP-R210L(DN) cells, respectively. In this regard, future studies are needed to elucidate the cross-talk between SP-A and GM-CSF (Shibata, et al., 2001, Chroneos and Shepherd, 1995, Blau, et al., 1994, Yoshida, et al., 2001), its role modulating alveolar macrophage function and local homeostasis, and whether PU.1 is the downstream effector of this interaction in vivo. Furthermore, it is noteworthy that a shorter $110 \mathrm{kDa}$ isoform of SP-R210 was shown to interact physically with the M-CSF receptor signaling complex in human U937 monocytic cells (Cross, et al., 2004), which do not express the L isoform (Yang, et al., 2005). Therefore, future studies are needed to explore the impact of $\mathrm{L}$ deletion and SP-R210 deletion mutagenesis in the PU.1/M-CSF receptor signaling pathway. This may contribute to dynamic modulation of immune activation threshold of alveolar and inflammatory macrophages with different expression of SP-R210 isoforms to modulate inflammation and host 
609 resistance to infection. Our study provides the framework for further studies to delineate intrinsic

610 and ligand-dependent mechanisms by which SP-R210 isoforms in macrophages regulate homeostatic

611 and inflammatory functions of resident macrophage populations.

612

613

$\begin{array}{lll}614 & 7 & \text { Conflict of Interest }\end{array}$

615 Zissis C. Chroneos is co-founder of Respana Therapeutic, Inc. (http://respana-therapeutics.com/) an

616 early-stage company developing therapeutics targeting SP-R210 isoforms.

617

\section{Author Contributions}

619 EY acquired, analyzed, graphed genomic data, and wrote the manuscript. YC and EY developed and 620 performed influenza infection assays and processed cells for RNAseq analysis. CS provided expertise

621 for chromatin immunoprecipitation experiments. JW produced and isolated SP-R210(KO) data using 622 CRISPR. YIA oversaw the generation of RNAseq and ChIP-derived libraries, acquisition RNAseq and 623 ChiPseq data, provided expertise for bioinformatics analysis, and read manuscript critically. ZT and YT 624 provided expertise and reagents for CRISPR knockout of SP-R210. TMU purified IAV, performed 625 experiments, and edited manuscript. SD provided reagents and expertise in analysis of epigenetic 626 data. ZC conceptualized, designed, contributed to bioinformatics analysis, led the study, and co-wrote 627 the manuscript.

628

6299 Funding

630 This work was funded in part by PHS grants HL128746, Pennsylvania Department of Health The 631 Children's Miracle Network, and the Department of Pediatrics Pennsylvania State University College 632 of Medicine.

633

63410 Acknowledgments 
We would like to thank Nate Schaffer and Joseph Bednarzyk from the Pennsylvania State University College of Medicine Flow Cytometry Core Facility as well as the Institute of Personalized Medicine for assistance with flow cytometry and genomic processes.

\section{References}

642

643

644

645

646

647

648

649

650

651

652

653

654

655

656

657

658

659

660

661

662

663

664

665

666

667

668

669

670

671

672

673

674

Sica, A., Mantovani, A. 2012. Macrophage plasticity and polarization: in vivo veritas. J Clin Invest $122,787$.

Italiani, P., Boraschi, D. 2014. From Monocytes to M1/M2 Macrophages: Phenotypical vs. Functional Differentiation. Front Immunol 5, 514.

Stout, R.D., Jiang, C., Matta, B., Tietzel, I., Watkins, S.K., Suttles, J. 2005. Macrophages sequentially change their functional phenotype in response to changes in microenvironmental influences. J Immunol 175, 342.

Hussell, T., Bell, T.J. 2014. Alveolar macrophages: plasticity in a tissue-specific context. Nat Rev Immunol 14, 81.

McQuattie-Pimentel, A.C., Ren, Z., Joshi, N., Watanabe, S., Stoeger, T., Chi, M., Lu, Z., Sichizya, L., Aillon, R.P., Chen, C.I., Soberanes, S., Chen, Z., Reyfman, P.A., Walter, J.M., Anekalla, K.R., Davis, J.M., Helmin, K.A., Runyan, C.E., Abdala-Valencia, H., Nam, K., Meliton, A.Y., Winter, D.R., Morimoto, R.I., Mutlu, G.M., Bharat, A., Perlman, H., Gottardi, C.J., Ridge, K.M., Chandel, N.S., Sznajder, J.I., Balch, W.E., Singer, B.D., Misharin, A.V., Budinger, G.R.S. 2021. The lung microenvironment shapes a dysfunctional response of alveolar macrophages in aging. J Clin Invest 131.

Upham, J.W., Strickland, D.H., Bilyk, N., Robinson, B.W., Holt, P.G. 1995. Alveolar macrophages from humans and rodents selectively inhibit T-cell proliferation but permit T-cell activation and cytokine secretion. Immunology 84, 142.

Kobzik, L., Godleski, J.J., Brain, J.D. 1990. Selective down-regulation of alveolar macrophage oxidative response to opsonin-independent phagocytosis. J Immunol 144, 4312.

Shibata, Y., Berclaz, P.Y., Chroneos, Z.C., Yoshida, M., Whitsett, J.A., Trapnell, B.C. 2001. GM-CSF regulates alveolar macrophage differentiation and innate immunity in the lung through PU.1. Immunity 15, 557.

Baker, A.D., Malur, A., Barna, B.P., Ghosh, S., Kavuru, M.S., Malur, A.G., Thomassen, M.J. 2010. Targeted PPAR \{gamma\} deficiency in alveolar macrophages disrupts surfactant catabolism. Journal of lipid research 51, 1325.

Chroneos, Z.C., Sever-Chroneos, Z., Shepherd, V.L. 2010. Pulmonary surfactant: an immunological perspective. Cell Physiol Biochem 25, 13.

Guilliams, M., De Kleer, I., Henri, S., Post, S., Vanhoutte, L., De Prijck, S., Deswarte, K., Malissen, B., Hammad, H., Lambrecht, B.N. 2013. Alveolar macrophages develop from fetal monocytes that differentiate into long-lived cells in the first week of life via GM-CSF. J Exp Med 210, 1977. 
675

676

677

678

679

680

681

682

683

684

685

686

687

688

689

690

691

692

693

694

695

696

697

698

699

700

701

702

703

704

705

706

707

708

709

710

711

712

713

714

715

716

717

718

719

720

Bates, S.R., Xu, J., Dodia, C., Fisher, A.B. 1997. Macrophages primed by overnight culture demonstrate a marked stimulation of surfactant protein A degradation. Am J Physiol 273, L831.

Schneider, C., Nobs, S.P., Kurrer, M., Rehrauer, H., Thiele, C., Kopf, M. 2014. Induction of the nuclear receptor PPAR-gamma by the cytokine GM-CSF is critical for the differentiation of fetal monocytes into alveolar macrophages. Nat Immunol 15, 1026.

Tan, S.Y., Krasnow, M.A. 2016. Developmental origin of lung macrophage diversity. Development 143, 1318.

He, W., Chen, C.J., Mullarkey, C.E., Hamilton, J.R., Wong, C.K., Leon, P.E., Uccellini, M.B., Chromikova, V., Henry, C., Hoffman, K.W., Lim, J.K., Wilson, P.C., Miller, M.S., Krammer, F., Palese, P., Tan, G.S. 2017. Alveolar macrophages are critical for broadly-reactive antibodymediated protection against influenza A virus in mice. Nat Commun 8, 846.

Kirby, A.C., Coles, M.C., Kaye, P.M. 2009. Alveolar macrophages transport pathogens to lung draining lymph nodes. J Immunol 183, 1983.

Roth, M.D., Golub, S.H. 1993. Human pulmonary macrophages utilize prostaglandins and transforming growth factor beta 1 to suppress lymphocyte activation. J Leukoc Biol 53, 366.

Schneider, C., Nobs, S.P., Heer, A.K., Kurrer, M., Klinke, G., van Rooijen, N., Vogel, J., Kopf, M. 2014. Alveolar macrophages are essential for protection from respiratory failure and associated morbidity following influenza virus infection. PLoS Pathog 10, e1004053.

Purnama, C., Ng, S.L., Tetlak, P., Setiagani, Y.A., Kandasamy, M., Baalasubramanian, S., Karjalainen, K., Ruedl, C. 2014. Transient ablation of alveolar macrophages leads to massive pathology of influenza infection without affecting cellular adaptive immunity. Eur J Immunol 44, 2003.

Halstead, E.S., Umstead, T.M., Davies, M.L., Kawasawa, Y.I., Silveyra, P., Howyrlak, J., Yang, L., Guo, W., Hu, S., Hewage, E.K., Chroneos, Z.C. 2018. GM-CSF overexpression after influenza a virus infection prevents mortality and moderates M1-like airway monocyte/macrophage polarization. Respir Res 19, 3.

Halstead, E.S., Chroneos, Z.C. 2015. Lethal influenza infection: Is a macrophage to blame? Expert Rev Anti Infect Ther, 1.

Casals, C., Garcia-Fojeda, B., Minutti, C.M. 2019. Soluble defense collagens: Sweeping up immune threats. Mol Immunol 112, 291.

Minutti, C.M., Knipper, J.A., Allen, J.E., Zaiss, D.M. 2017. Tissue-specific contribution of macrophages to wound healing. Semin Cell Dev Biol 61, 3.

Canadas, O., Olmeda, B., Alonso, A., Perez-Gil, J. 2020. Lipid-Protein and Protein-Protein Interactions in the Pulmonary Surfactant System and Their Role in Lung Homeostasis. Int J Mol Sci 21.

Autilio, C., Perez-Gil, J. 2019. Understanding the principle biophysics concepts of pulmonary surfactant in health and disease. Arch Dis Child Fetal Neonatal Ed 104, F443.

Nguyen, H.A., Rajaram, M.V., Meyer, D.A., Schlesinger, L.S. 2012. Pulmonary surfactant protein A and surfactant lipids upregulate IRAK-M, a negative regulator of TLR-mediated inflammation in human macrophages. Am J Physiol Lung Cell Mol Physiol 303, L608.

Phelps, D.S., Umstead, T.M., Silveyra, P., Hu, S., Wang, G., Floros, J. 2013. Differences in the alveolar macrophage proteome in transgenic mice expressing human SP-A1 and SP-A2. J Proteom Genom Res 1, 2.

Phelps, D.S., Umstead, T.M., Quintero, O.A., Yengo, C.M., Floros, J. 2011. In vivo rescue of alveolar macrophages from SP-A knockout mice with exogenous SP-A nearly restores a wild type intracellular proteome; actin involvement. Proteome Sci 9, 67. 
721

722

723

724

725

726

727

728

729

730

731

732

733

734

735

736

737

738

739

740

741

742

743

744

745

746

747

748

749

750

751

752

753

754

755

756

757

758

759

760

761

762

763

764

765

766

Minutti, C.M., Garcia-Fojeda, B., Saenz, A., de Las Casas-Engel, M., Guillamat-Prats, R., de Lorenzo, A., Serrano-Mollar, A., Corbi, A.L., Casals, C. 2016. Surfactant Protein A Prevents IFNgamma/IFN-gamma Receptor Interaction and Attenuates Classical Activation of Human Alveolar Macrophages. J Immunol 197, 590.

Francisco, D., Wang, Y., Conway, M., Hurbon, A.N., Dy, A.B.C., Addison, K.J., Chu, H.W., Voelker, D.R., Ledford, J.G., Kraft, M. 2020. Surfactant Protein-A Protects against IL-13-Induced Inflammation in Asthma. J Immunol 204, 2829.

Younis, U.S., Chu, H.W., Kraft, M., Ledford, J.G. 2020. A 20-mer peptide derived from the lectin domain of SP-A2 decreases TNF-alpha production during Mycoplasma pneumoniae infection. Infect Immun.

Moulakakis, C., Steinhauser, C., Biedziak, D., Freundt, K., Reiling, N., Stamme, C. 2016. Surfactant Protein A Enhances Constitutive Immune Functions of Clathrin Heavy Chain and Clathrin Adaptor Protein 2. Am J Respir Cell Mol Biol 55, 92.

Moulakakis, C., Stamme, C. 2009. Role of clathrin-mediated endocytosis of surfactant protein A by alveolar macrophages in intracellular signaling. Am J Physiol Lung Cell Mol Physiol 296, L430.

Wu, Y., Adam, S., Hamann, L., Heine, H., Ulmer, A.J., Buwitt-Beckmann, U., Stamme, C. 2004. Accumulation of inhibitory kappaB-alpha as a mechanism contributing to the antiinflammatory effects of surfactant protein-A. Am J Respir Cell Mol Biol 31, 587.

Henning, L.N., Azad, A.K., Parsa, K.V., Crowther, J.E., Tridandapani, S., Schlesinger, L.S. 2008. Pulmonary Surfactant Protein A Regulates TLR Expression and Activity in Human Macrophages. J Immunol 180, 7847.

Gil, M., McCormack, F.X., Levine, A.M. 2009. Surfactant protein-A modulates cell surface expression of CR3 on alveolar macrophages and enhances CR3-mediated phagocytosis. J Biol Chem.

Yang, L., Carrillo, M., Wu, Y.M., DiAngelo, S.L., Silveyra, P., Umstead, T.M., Halstead, E.S., Davies, M.L., Hu, S., Floros, J., McCormack, F.X., Christensen, N.D., Chroneos, Z.C. 2015. SP-R210 (Myo18A) Isoforms as Intrinsic Modulators of Macrophage Priming and Activation. PLoS One 10, e0126576.

Weikert, L.F., Lopez, J.P., Abdolrasulnia, R., Chroneos, Z.C., Shepherd, V.L. 2000. Surfactant protein A enhances mycobacterial killing by rat macrophages through a nitric oxide-dependent pathway. Am J Physiol Lung Cell Mol Physiol 279, L216.

Weikert, L.F., Edwards, K., Chroneos, Z.C., Hager, C., Hoffman, L., Shepherd, V.L. 1997. SP-A enhances uptake of bacillus Calmette-Guerin by macrophages through a specific SP-A receptor. Am J Physiol 272, L989.

Minutti, C.M., Jackson-Jones, L.H., Garcia-Fojeda, B., Knipper, J.A., Sutherland, T.E., Logan, N., Rinqvist, E., Guillamat-Prats, R., Ferenbach, D.A., Artigas, A., Stamme, C., Chroneos, Z.C., Zaiss, D.M., Casals, C., Allen, J.E. 2017. Local amplifiers of IL-4Ralpha-mediated macrophage activation promote repair in lung and liver. Science 356, 1076.

Mori, K., Furusawa, T., Okubo, T., Inoue, T., Ikawa, S., Yanai, N., Mori, K.J., Obinata, M. 2003. Genome structure and differential expression of two isoforms of a novel PDZ-containing myosin (MysPDZ) (Myo18A). J Biochem 133, 405.

Yang, C.H., Szeliga, J., Jordan, J., Faske, S., Sever-Chroneos, Z., Dorsett, B., Christian, R.E., Settlage, R.E., Shabanowitz, J., Hunt, D.F., Whitsett, J.A., Chroneos, Z.C. 2005. Identification of the surfactant protein A receptor 210 as the unconventional myosin 18A. J Biol Chem 280, 34447.

Szeliga, J., Jordan, J., Yang, C.H., Sever-Chroneos, Z., Chroneos, Z.C. 2005. Bacterial expression of recombinant MyoXVIIIA domains. Anal Biochem 346, 179. 
Taft, M.H., Latham, S.L. 2020. Myosin XVIII. Adv Exp Med Biol 1239, 421.

Lee, I.C., Leung, T., Tan, I. 2014. Adaptor protein LRAP25 mediates myotonic dystrophy kinaserelated Cdc42-binding kinase (MRCK) regulation of LIMK1 protein in lamellipodial F-actin dynamics. J Biol Chem 289, 26989.

Ng, M.M., Dippold, H.C., Buschman, M.D., Noakes, C.J., Field, S.J. 2013. GOLPH3L antagonizes GOLPH3 to determine Golgi morphology. Mol Biol Cell 24, 796.

Horsthemke, M., Nutter, L.M.J., Bachg, A.C., Skryabin, B.V., Honnert, U., Zobel, T., Bogdan, S., Stoll, M., Seidl, M.D., Muller, F.U., Ravens, U., Unger, A., Linke, W.A., van Gorp, P.R.R., de Vries, A.A.F., Bahler, M., Hanley, P.J. 2019. A novel isoform of myosin 18A (Myo18Agamma) is an essential sarcomeric protein in mouse heart. J Biol Chem 294, 7202.

Cross, M., Csar, X.F., Wilson, N.J., Manes, G., Addona, T.A., Marks, D.C., Whitty, G.A., Ashman, K., Hamilton, J.A. 2004. A novel $110 \mathrm{kDa}$ form of myosin XVIIIA (MysPDZ) is tyrosinephosphorylated after colony-stimulating factor-1 receptor signalling. Biochem J 380, 243. De Masson, A., Giustiniani, J., Marie-Cardine, A., Bouaziz, J.D., Dulphy, N., Gossot, D., Validire, P., Tazi, A., Garbar, C., Bagot, M., Merrouche, Y., Bensussan, A. 2016. Identification of CD245 as myosin $18 \mathrm{~A}$, a receptor for surfactant $\mathrm{A}$ : A novel pathway for activating human NK lymphocytes. Oncoimmunology 5, e1127493.

Samten, B., Townsend, J.C., Sever-Chroneos, Z., Pasquinelli, V., Barnes, P.F., Chroneos, Z.C. 2008. An antibody against the surfactant protein A (SP-A)-binding domain of the SP-A receptor inhibits T cell-mediated immune responses to Mycobacterium tuberculosis. J Leukoc Biol 84, 115.

Chroneos, Z., Shepherd, V.L. 1995. Differential regulation of the mannose and SP-A receptors on macrophages. Am J Physiol 269, L721.

Jean Beltran, P.M., Mathias, R.A., Cristea, I.M. 2016. A Portrait of the Human Organelle Proteome In Space and Time during Cytomegalovirus Infection. Cell Syst 3, 361.

Sever-Chroneos, Z., Krupa, A., Davis, J., Hasan, M., Yang, C.H., Szeliga, J., Herrmann, M., Hussain, M., Geisbrecht, B.V., Kobzik, L., Chroneos, Z.C. 2011. Surfactant protein A (SP-A)-mediated clearance of Staphylococcus aureus involves binding of SP-A to the staphylococcal adhesin eap and the macrophage receptors SP-A receptor 210 and scavenger receptor class A. J Biol Chem 286, 4854.

Borron, P., McCormack, F.X., Elhalwagi, B.M., Chroneos, Z.C., Lewis, J.F., Zhu, S., Wright, J.R., Shepherd, V.L., Possmayer, F., Inchley, K., Fraher, L.J. 1998. Surfactant protein A inhibits T cell proliferation via its collagen-like tail and a 210-kDa receptor. Am J Physiol 275, L679.

Chroneos, Z.C., Abdolrasulnia, R., Whitsett, J.A., Rice, W.R., Shepherd, V.L. 1996. Purification of a cell-surface receptor for surfactant protein A. J Biol Chem 271, 16375.

Lopez-Sanchez, A., Saenz, A., Casals, C. 2010. Surfactant protein A (SP-A)-tacrolimus complexes have a greater anti-inflammatory effect than either SP-A or tacrolimus alone on human macrophage-like U937 cells. European journal of pharmaceutics and biopharmaceutics : official journal of Arbeitsgemeinschaft fur Pharmazeutische Verfahrenstechnik e.V.

Stamme, C., Walsh, E., Wright, J.R. 2000. Surfactant protein A differentially regulates IFN-gammaand LPS-induced nitrite production by rat alveolar macrophages. Am J Respir Cell Mol Biol $23,772$.

Sever-Chroneos, Z., Murthy, A., Davis, J., Florence, J.M., Kurdowska, A., Krupa, A., Tichelaar, J.W., White, M.R., Hartshorn, K.L., Kobzik, L., Whitsett, J.A., Chroneos, Z.C. 2011. GM-CSF modulates pulmonary resistance to influenza $A$ infection. Antiviral Res 92, 319.

Fino, K.K., Yang, L., Silveyra, P., Hu, S., Umstead, T.M., DiAngelo, S., Halstead, E.S., Cooper, T.K., Abraham, T., Takahashi, Y., Zhou, Z., Wang, H.G., Chroneos, Z.C. 2017. SH3GLB2/endophilin 
B2 regulates lung homeostasis and recovery from severe influenza A virus infection. Sci Rep 7, 7262 .

Kim, D., Langmead, B., Salzberg, S.L. 2015. HISAT: a fast spliced aligner with low memory requirements. Nat Methods 12, 357.

Liao, Y., Smyth, G.K., Shi, W. 2019. The R package Rsubread is easier, faster, cheaper and better for alignment and quantification of RNA sequencing reads. Nucleic Acids Res 47, e47.

Love, M.I., Huber, W., Anders, S. 2014. Moderated estimation of fold change and dispersion for RNA-seq data with DESeq2. Genome Biol 15, 550.

Kanehisa, M., Goto, S. 2000. KEGG: kyoto encyclopedia of genes and genomes. Nucleic Acids Res 28, 27.

Korotkevich, G., Sukhov, V., Sergushichev, A. 2019. Fast gene set enrichment analysis. bioRxiv, 060012.

Wang, H., Song, C., Ding, Y., Pan, X., Ge, Z., Tan, B.H., Gowda, C., Sachdev, M., Muthusami, S., Ouyang, H., Lai, L., Francis, O.L., Morris, C.L., Abdel-Azim, H., Dorsam, G., Xiang, M., Payne, K.J., Dovat, S. 2016. Transcriptional Regulation of JARID1B/KDM5B Histone Demethylase by Ikaros, Histone Deacetylase 1 (HDAC1), and Casein Kinase 2 (CK2) in B-cell Acute Lymphoblastic Leukemia. J Biol Chem 291, 4004.

Zhu, L.J., Gazin, C., Lawson, N.D., Pages, H., Lin, S.M., Lapointe, D.S., Green, M.R. 2010. ChIPpeakAnno: a Bioconductor package to annotate ChIP-seq and ChIP-chip data. BMC Bioinformatics 11, 237.

Yu, G., Wang, L.G., He, Q.Y. 2015. ChIPseeker: an R/Bioconductor package for ChIP peak annotation, comparison and visualization. Bioinformatics 31, 2382.

Yu, G., He, Q.Y. 2016. ReactomePA: an R/Bioconductor package for reactome pathway analysis and visualization. Mol Biosyst 12, 477.

Glass, C.K., Natoli, G. 2016. Molecular control of activation and priming in macrophages. Nat Immunol 17, 26.

Hoogenkamp, M., Krysinska, H., Ingram, R., Huang, G., Barlow, R., Clarke, D., Ebralidze, A., Zhang, P., Tagoh, H., Cockerill, P.N., Tenen, D.G., Bonifer, C. 2007. The Pu.1 locus is differentially regulated at the level of chromatin structure and noncoding transcription by alternate mechanisms at distinct developmental stages of hematopoiesis. Mol Cell Biol 27, 7425.

Imperato, M.R., Cauchy, P., Obier, N., Bonifer, C. 2015. The RUNX1-PU.1 axis in the control of hematopoiesis. Int J Hematol 101, 319.

Petrovick, M.S., Hiebert, S.W., Friedman, A.D., Hetherington, C.J., Tenen, D.G., Zhang, D.E. 1998. Multiple functional domains of AML1: PU.1 and C/EBPalpha synergize with different regions of AML1. Mol Cell Biol 18, 3915.

Schmidt, S.V., Krebs, W., Ulas, T., Xue, J., Bassler, K., Gunther, P., Hardt, A.L., Schultze, H., Sander, J., Klee, K., Theis, H., Kraut, M., Beyer, M., Schultze, J.L. 2016. The transcriptional regulator network of human inflammatory macrophages is defined by open chromatin. Cell Res 26, 151.

Berclaz, P.Y., Carey, B., Fillipi, M.D., Wernke-Dollries, K., Geraci, N., Cush, S., Richardson, T., Kitzmiller, J., O'Connor, M., Hermoyian, C., Korfhagen, T., Whitsett, J.A., Trapnell, B.C. 2007. GM-CSF regulates a PU.1-dependent transcriptional program determining the pulmonary response to LPS. American journal of respiratory cell and molecular biology 36, 114.

Cheng, J.X., Anastasi, J., Watanabe, K., Kleinbrink, E.L., Grimley, E., Knibbs, R., Shen, Q.J., Vardiman, J.W. 2013. Genome-wide profiling reveals epigenetic inactivation of the PU.1 pathway by 
histone H3 lysine 27 trimethylation in cytogenetically normal myelodysplastic syndrome. Leukemia 27, 1291.

Burda, P., Vargova, J., Curik, N., Salek, C., Papadopoulos, G.L., Strouboulis, J., Stopka, T. 2016. GATA1 Inhibits PU.1 Gene via DNA and Histone H3K9 Methylation of Its Distal Enhancer in Erythroleukemia. PLoS One 11, e0152234.

Tagore, M., McAndrew, M.J., Gjidoda, A., Floer, M. 2015. The Lineage-Specific Transcription Factor PU.1 Prevents Polycomb-Mediated Heterochromatin Formation at Macrophage-Specific Genes. Mol Cell Biol 35, 2610.

K, D., VR, P., P, R., X, X., P, B. 2011. MotifMap: integrative genome-wide maps of regulatory motif sites for model species. BMC bioinformatics 12 .

G, M., S, S., AJ, T., J, T., SJ, M., M, W., Y, G., C, F., J, B., G, K., C, P., V, O., S, T., DG, T., C, P., T, E. 2013. Dynamic analysis of gene expression and genome-wide transcription factor binding during lineage specification of multipotent progenitors. Cell stem cell 13.

V, B. 2016. Analysis of Genomic Sequence Motifs for Deciphering Transcription Factor Binding and Transcriptional Regulation in Eukaryotic Cells. Frontiers in genetics 7.

Carey, B., Staudt, M.K., Bonaminio, D., van der Loo, J.C., Trapnell, B.C. 2007. PU.1 redirects adenovirus to lysosomes in alveolar macrophages, uncoupling internalization from infection. Journal of immunology 178, 2440.

Umstead, T.M., Hewage, E.K., Mathewson, M., Beaudoin, S., Chroneos, Z.C., Wang, M., Halstead, E.S. 2020. Lower respiratory tract delivery, airway clearance, and preclinical efficacy of inhaled GM-CSF in a postinfluenza pneumococcal pneumonia model. Am J Physiol Lung Cell Mol Physiol 318, L571.

Huang, F.F., Barnes, P.F., Feng, Y., Donis, R., Chroneos, Z.C., Idell, S., Allen, T., Perez, D.R., Whitsett, J.A., Dunussi-Joannopoulos, K., Shams, H. 2011. GM-CSF in the lung protects against lethal influenza infection. Am J Respir Crit Care Med 184, 259.

Marvin, S.A., Russier, M., Huerta, C.T., Russell, C.J., Schultz-Cherry, S. 2017. Influenza Virus Overcomes Cellular Blocks To Productively Replicate, Impacting Macrophage Function. J Virol 91.

Cline, T.D., Beck, D., Bianchini, E. 2017. Influenza virus replication in macrophages: balancing protection and pathogenesis. J Gen Virol 98, 2401.

Pradere, J.P., Hernandez, C., Koppe, C., Friedman, R.A., Luedde, T., Schwabe, R.F. 2016. Negative regulation of NF-kappaB p65 activity by serine 536 phosphorylation. Sci Signal 9, ra85.

Song, Y.J., Jen, K.Y., Soni, V., Kieff, E., Cahir-McFarland, E. 2006. IL-1 receptor-associated kinase 1 is critical for latent membrane protein 1-induced p65/RelA serine 536 phosphorylation and NFkappaB activation. Proc Natl Acad Sci U S A 103, 2689.

Schmeck, B., Zahlten, J., Moog, K., van Laak, V., Huber, S., Hocke, A.C., Opitz, B., Hoffmann, E., Kracht, M., Zerrahn, J., Hammerschmidt, S., Rosseau, S., Suttorp, N., Hippenstiel, S. 2004. Streptococcus pneumoniae-induced p38 MAPK-dependent phosphorylation of RelA at the interleukin-8 promotor. J Biol Chem 279, 53241.

Oishi, Y., Spann, N.J., Link, V.M., Muse, E.D., Strid, T., Edillor, C., Kolar, M.J., Matsuzaka, T., Hayakawa, S., Tao, J., Kaikkonen, M.U., Carlin, A.F., Lam, M.T., Manabe, I., Shimano, H., Saghatelian, A., Glass, C.K. 2017. SREBP1 Contributes to Resolution of Pro-inflammatory TLR4 Signaling by Reprogramming Fatty Acid Metabolism. Cell Metab 25, 412.

Koundouros, N., Poulogiannis, G. 2020. Reprogramming of fatty acid metabolism in cancer. Br J Cancer 122, 4. 
903

904

905

906

907

908

909

910

911

912

913

914

915

916

917

918

919

920

921

922

923

924

925

926

927

928

929

930

931

932

933

934

935

936

937

938

939

940

941

942

943

944

945

946

947

948

Cucchi, D., Camacho-Munoz, D., Certo, M., Pucino, V., Nicolaou, A., Mauro, C. 2019. Fatty acids from energy substrates to key regulators of cell survival, proliferation and effector function. Cell Stress 4, 9.

Spadaro, O., Camell, C.D., Bosurgi, L., Nguyen, K.Y., Youm, Y.H., Rothlin, C.V., Dixit, V.D. 2017. IGF1 Shapes Macrophage Activation in Response to Immunometabolic Challenge. Cell Rep 19, 225.

Kralova Lesna, I., Kralova, A., Cejkova, S., Fronek, J., Petras, M., Sekerkova, A., Thieme, F., Janousek, L., Poledne, R. 2016. Characterisation and comparison of adipose tissue macrophages from human subcutaneous, visceral and perivascular adipose tissue. J Transl Med 14, 208.

Cao, Q., Rong, S., Repa, J.J., St Clair, R., Parks, J.S., Mishra, N. 2014. Histone deacetylase 9 represses cholesterol efflux and alternatively activated macrophages in atherosclerosis development. Arterioscler Thromb Vasc Biol 34, 1871.

Li, X., Zhang, Q., Ding, Y., Liu, Y., Zhao, D., Zhao, K., Shen, Q., Liu, X., Zhu, X., Li, N., Cheng, Z., Fan, G., Wang, Q., Cao, X. 2016. Methyltransferase Dnmt3a upregulates HDAC9 to deacetylate the kinase TBK1 for activation of antiviral innate immunity. Nat Immunol 17, 806.

Zhang, N., Sauve, A.A. 2018. Regulatory Effects of NAD(+) Metabolic Pathways on Sirtuin Activity. Prog Mol Biol Transl Sci 154, 71.

Karpurapu, M., Wang, X., Deng, J., Park, H., Xiao, L., Sadikot, R.T., Frey, R.S., Maus, U.A., Park, G.Y., Scott, E.W., Christman, J.W. 2011. Functional PU.1 in macrophages has a pivotal role in NFkappaB activation and neutrophilic lung inflammation during endotoxemia. Blood 118, 5255.

Liu, J., Ma, X. 2006. Interferon regulatory factor 8 regulates RANTES gene transcription in cooperation with interferon regulatory factor-1, NF-kappaB, and PU.1. J Biol Chem 281, 19188.

Rosa, A., Ballarino, M., Sorrentino, A., Sthandier, O., De Angelis, F.G., Marchioni, M., Masella, B., Guarini, A., Fatica, A., Peschle, C., Bozzoni, I. 2007. The interplay between the master transcription factor PU.1 and miR-424 regulates human monocyte/macrophage differentiation. Proc Natl Acad Sci U S A 104, 19849.

Celada, A., Borras, F.E., Soler, C., Lloberas, J., Klemsz, M., van Beveren, C., McKercher, S., Maki, R.A. 1996. The transcription factor PU.1 is involved in macrophage proliferation. J Exp Med 184, 61.

Ha, S.D., Cho, W., DeKoter, R.P., Kim, S.O. 2019. The transcription factor PU.1 mediates enhancerpromoter looping that is required for IL-1beta eRNA and mRNA transcription in mouse melanoma and macrophage cell lines. J Biol Chem 294, 17487.

Qian, F., Deng, J., Lee, Y.G., Zhu, J., Karpurapu, M., Chung, S., Zheng, J.N., Xiao, L., Park, G.Y., Christman, J.W. 2015. The transcription factor PU.1 promotes alternative macrophage polarization and asthmatic airway inflammation. J Mol Cell Biol 7, 557.

Rothenberg, E.V., Hosokawa, H., Ungerback, J. 2019. Mechanisms of Action of Hematopoietic Transcription Factor PU.1 in Initiation of T-Cell Development. Front Immunol 10, 228.

Ghisletti, S., Barozzi, I., Mietton, F., Polletti, S., De Santa, F., Venturini, E., Gregory, L., Lonie, L., Chew, A., Wei, C.L., Ragoussis, J., Natoli, G. 2010. Identification and characterization of enhancers controlling the inflammatory gene expression program in macrophages. Immunity 32, 317.

van Riel, B., Rosenbauer, F. 2014. Epigenetic control of hematopoiesis: the PU.1 chromatin connection. Biol Chem 395, 1265.

Leddin, M., Perrod, C., Hoogenkamp, M., Ghani, S., Assi, S., Heinz, S., Wilson, N.K., Follows, G., Schonheit, J., Vockentanz, L., Mosammam, A.M., Chen, W., Tenen, D.G., Westhead, D.R., 

the PU.1 locus in B cells and myeloid cells. Blood 117, 2827.

Rojo, R., Pridans, C., Langlais, D., Hume, D.A. 2017. Transcriptional mechanisms that control expression of the macrophage colony-stimulating factor receptor locus. Clin Sci (Lond) 131, 2161.

Schroder, K., Lichtinger, M., Irvine, K.M., Brion, K., Trieu, A., Ross, I.L., Ravasi, T., Stacey, K.J., Rehli, M., Hume, D.A., Sweet, M.J. 2007. PU.1 and ICSBP control constitutive and IFN-gammaregulated TIr9 gene expression in mouse macrophages. J Leukoc Biol 81, 1577.

Lichanska, A.M., Browne, C.M., Henkel, G.W., Murphy, K.M., Ostrowski, M.C., McKercher, S.R., Maki, R.A., Hume, D.A. 1999. Differentiation of the mononuclear phagocyte system during mouse embryogenesis: the role of transcription factor PU.1. Blood 94, 127.

Ross, I.L., Yue, X., Ostrowski, M.C., Hume, D.A. 1998. Interaction between PU.1 and another Ets family transcription factor promotes macrophage-specific Basal transcription initiation. J Biol Chem 273, 6662.

Reddy, M.A., Yang, B.S., Yue, X., Barnett, C.J., Ross, I.L., Sweet, M.J., Hume, D.A., Ostrowski, M.C. 1994. Opposing actions of c-ets/PU.1 and c-myb protooncogene products in regulating the macrophage-specific promoters of the human and mouse colony-stimulating factor-1 receptor (c-fms) genes. J Exp Med 180, 2309.

Minderjahn, J., Schmidt, A., Fuchs, A., Schill, R., Raithel, J., Babina, M., Schmidl, C., Gebhard, C., Schmidhofer, S., Mendes, K., Ratermann, A., Glatz, D., Nutzel, M., Edinger, M., Hoffmann, P., Spang, R., Langst, G., Imhof, A., Rehli, M. 2020. Mechanisms governing the pioneering and redistribution capabilities of the non-classical pioneer PU.1. Nat Commun 11, 402.

McAndrew, M.J., Gjidoda, A., Tagore, M., Miksanek, T., Floer, M. 2016. Chromatin Remodeler Recruitment during Macrophage Differentiation Facilitates Transcription Factor Binding to Enhancers in Mature Cells. J Biol Chem 291, 18058.

Blau, H., Riklis, S., Kravtsov, V., Kalina, M. 1994. Secretion of cytokines by rat alveolar epithelial cells: possible regulatory role for SP-A. Am J Physiol 266, L148.

Yoshida, M., Ikegami, M., Reed, J.A., Chroneos, Z.C., Whitsett, J.A. 2001. GM-CSF regulates protein and lipid catabolism by alveolar macrophages. Am J Physiol Lung Cell Mol Physiol 280, L379.

\section{Figures}

980 Figure 1. Differentially Expressed genes are associated with upregulation of Innate Immune Sensing

981 Pathways. (a) Cells were cultured overnight a $2 \mathrm{E} 5$ cells/well and removed using Cell Dissociation Media. Cells were washed, blocked with BD Mouse Fc Block, and stained with fluorescent antibodies against specific cell surface markers. Stained cells were analyzed using a LSR II flow cytometer with compensation and gating analysis performed on FlowJo $v$ 9.9.5. Data plotted is mean of mean fluorescence intensity \pm S.E. $(n=3), * *$, adjusted $p$-value $<0.005$ compared to WT; ***, adjusted $p$ - 
using featurecounts. Count data was then compared between genotypes with three replciates per cell type using deseq2. Differently expressed genes between SP-R210 (DN) and WT cells (bwere filtered by $p$-value<0.05. These gene sets were then filtered using the MGI Immune Genes database to elucidate differentially expressed immune genes (c - SP-R210 (DN) vs WT) The genes were also labeled in red in (b). Differentially expressed RNA genes were mapped to KEGG pathways using the fgsea R package. (d) Upregulated pathways were compared between SP-R210 L and WT cells. Enrichment plots for Cytosolic DNA Sensing Pathway and TLR Signaling Pathway were included to show enrichment in genes associated with these gene sets. (e) The enrichment scores for the 10 disease associated pathways with the lowest p-values were plotted for SP-R210 (DN) vs WT cells.

Figure 2. PU.1 binding across the genome is altered with SP-R210 depletion. ChIP was used to precipitate PU.1-bound genomic regions, then sequenced and aligned to the mm10 genome. Concordant peaks between two experimental replicates determined using overlappingpeaks function of ChIPPeakAnno were used for further analysis. (a) Peaks between WT and SP-R210L(DN) cells were compared using ChIPPeakAnno to identify the concordance in peaks between the two genotypes, showing 6140 peaks consistent with both genotypes, and 5365 peaks unique to SP-R210L(DN) cells. The peak distribution across genome was increased in SP-R210L(DN) cells (a). (b) Using Chipseeker, the identified peaks were associated with genomic features for WT and SP-R210 (DN) cells showed decrease PU.1 binding in promoter regions, but with slightly increased binding in 3' UTR, Exon, and Intron regions. (c) Association between unique ChIP peaks in each cell type and RNA expression. Of the 5365 PU.1 peaks unique to SP-R210 (DN) cells, 437 peaks were associated with RNA transcripts upregulated in WT cells, while 573 peaks were associated with RNA transcripts upregulated in SPR210 (DN) cells. Of 1011 PU.1 peaks unique to WT cells, 260 peaks were associated with genes with upregulated RNA transcripts in WT cells, and 49 peaks associated with upregulated in SP-R210L(DN) cells. (d) PU.1 associated genes were mapped to Reactome pathways using ReactomePA. Pathway enrichment scores and p-values for WT and SP-R210L(DN) cells were plotted in a heat map; each performed for both WT and SP-R210 (DN) cells, showing increased H3k4me3 marks in SP-R210L(DN) cells. (b) Genomic features associated with H3K4me3 marks were analyzed for both cell types, showing decreased H3K4me3 marks in promoter regions, but increased in intron and intergenic 
regions. This analysis was repeated for H3K9me3 (c, d) and H3K27me3 (e, f) methylation marks. For both H3K9me3 and H3K27me3, there were decreased amounts of these marks in SP-R210L(DN) cells, with similar changes in genomic distribution; there were decreased H3K9me3 and H3K27me3 marks in promoter regions, but increased in Exon, Intron, and Intergenic regions. Using ChIPPeakAnno, it was seen that of the H3K4me marks, only a small proportion is associated with PU.1 peaks in both WT (g) and SP-R210,(DN) (h) cells.

1025

1026

Figure 4. PU.1 and H3K4me3 peaks Association with Genes are Altered with SP-R210 (DN) cells. (a) Bedgraphs were generated for PU.1 and H3K4me3 ChIP and mapped to UCSC mm10 annotated genome. Viewing TLR5 on the UCSC genome browser revealed increased PU.1 and H3K4me3 binding at the promoter region of TLR5 in SP-R210L(DN) cells. Additional bedgraphs of TLR genes can be found in Supplemental Figure 5, Supplemental Figure 6. (b) PU.1 is known to bind its own enhancer region; visualizing PU.1 on the genome browser revealed PU.1 binding sites in the enhancer region of PU.1 in both WT and SP-R210 (DN) cells. (c) Investigating the Myo18A gene revealed several PU.1 peaks in both WT and SP-R210L(DN) cells of varying intensities. H3K4me3 peaks were found at the promoter region of Myo18a, as well as an internal start site. Highlighted in light blue is a predicted PU.1 binding site (UCI Motifmap), with the sequence depicted below. The sequence of a PU.1 peak present internal to Myo18A is also depicted. Within the sequence, a canonical PU.1 binding motif is highlighted in dark

Figure 5. IAV infection affects PU.1 binding differently in SP-R210 (DN) cells than WT cells. (a) PU.1 peaks were compared between uninfected and infected WT and SP-R210 (DN) cells to determine which peaks were similar or unique to each condition; infection reduces PU.1 binding in both WT and SP-R210 (DN) cells. (b) IAV infection affects WT and SP-R210 (DN) cells differently; while PU.1 binding with IAV infection has many shared regions with uninfected cells, some unique PU.1 bound regions in WT and SP-R210L(DN) cells were identified with infection. IAV infected WT and SP-R210L(DN) cells showed a majority or PU.1 bound regions to be similar, but each cell type also had numerous peaks that were unique with IAV infection. (c) PU.1 binding was mapped to genomic features for infected and uninfected WT and SP-R210 (DN) cells. Mapping revealed increased distribution of PU.1 binding to promoter regions in WT and SP-R210 (DN) cells, with concomitant decreases in Intron and Intergenic regions. (d) PU.1 associated regions were mapped to Reactome pathways; Pathway 
1050 enrichment scores and p-values for WT and SP-R210 L(DN) cells were plotted in a heat map; each

1051 pathway was associated to larger Reactome pathway families.

1053 Figure 6. SP-R210 knockdown alters phosphorylation of immune signaling molecules (a) Clarified 1054 cell lysates from WT and SP-R210 (DN) cells infected with PR8 for 3, 6, 12, and 24 hours were probed 1055 for phosphorylated and total IRF3 (a), IRF7 (b), NFאB p65 subunit (c, d) and P38 (e). (a) SP-R210L(DN) 1056 cells show a trend towards increased baseline IRF3 phosphorylation, but less IRF3 phosphorylation at $105724 \mathrm{HPI}(\mathrm{n}=2)$. (b) SP-R210 (DN) cells showed increased IRF7 phosphorylation at baseline, with 1058 significant increases at 12 and $24 \mathrm{HPI}(\mathrm{n}=3)(\mathbf{c}$, d) SP-R210_(DN) cells showed increased Ser276 1059 phosphorylation (c), but decreased Ser536 (d), of NFkB p65 compared with WT at baseline and 1060 throughout infection. (n=3) (e) WT cells exhibited increased phosphorylated P38 at 24 hours post 1061 infection compared to SP-R210L(DN) cells ( $n=3)$. Statistical significance determined by 2-way ANOVA. $1062 * *$, p-value <0.005 comparing between WT and SP-R210L(DN); ***, p-value<0.005 comparing 1063 between WT and SP-R210 (DN); +, p-value <0.05 comparing between uninfected and infected time 1064 point; ++, p-value <0.005 comparing between uninfected and infected time point; +++, p-value $1065<0.0005$ comparing between uninfected and infected time point; ++++, p-value <0.00005 comparing 1066 between uninfected and infected time point

\section{Data Availability Statement}

1069 The datasets for this study can be found on GEO []. 
Figure 1

a)
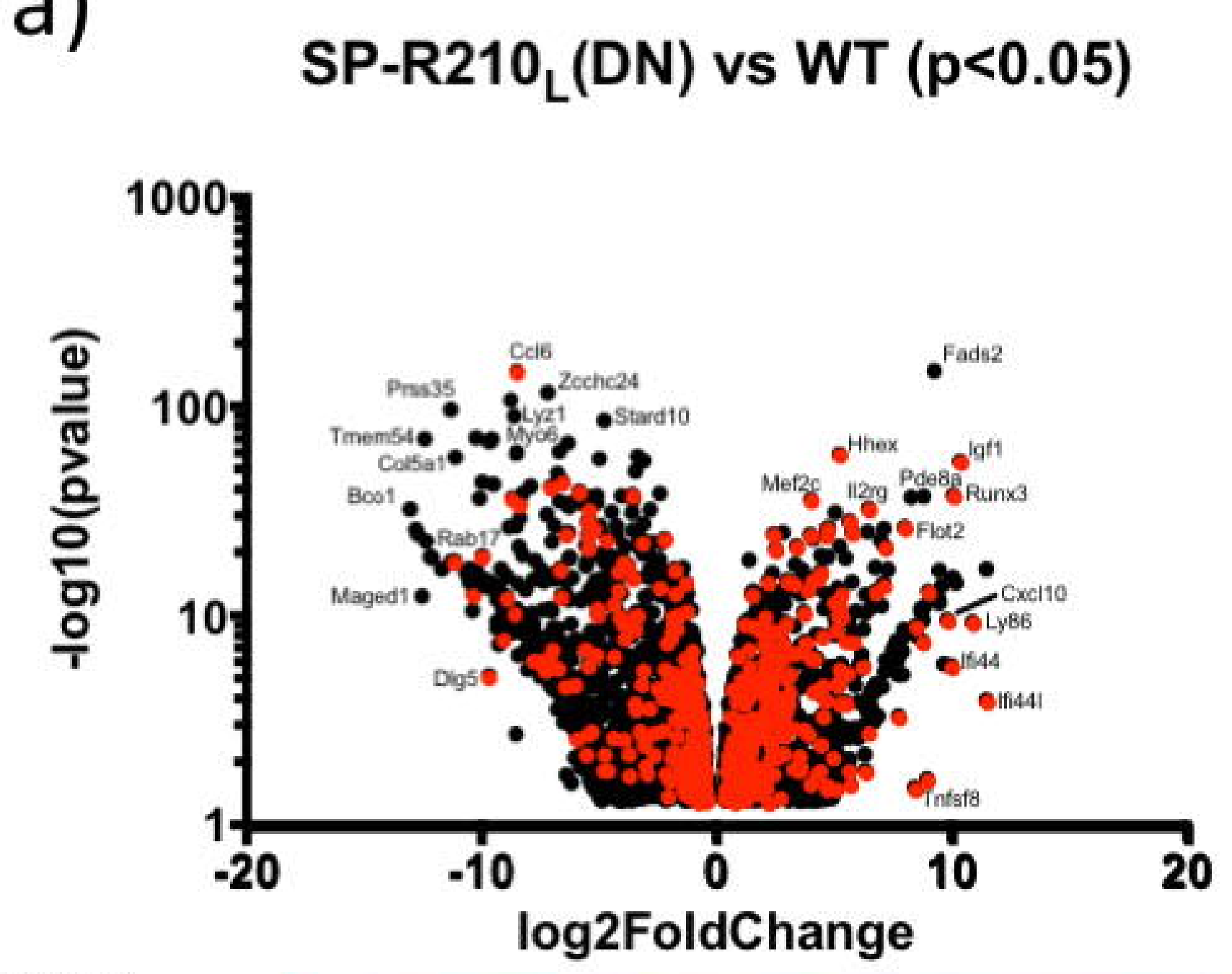

WT Expr. DN Expr.

c)

$$
\text { SP-R210 (DN) vs WT }
$$

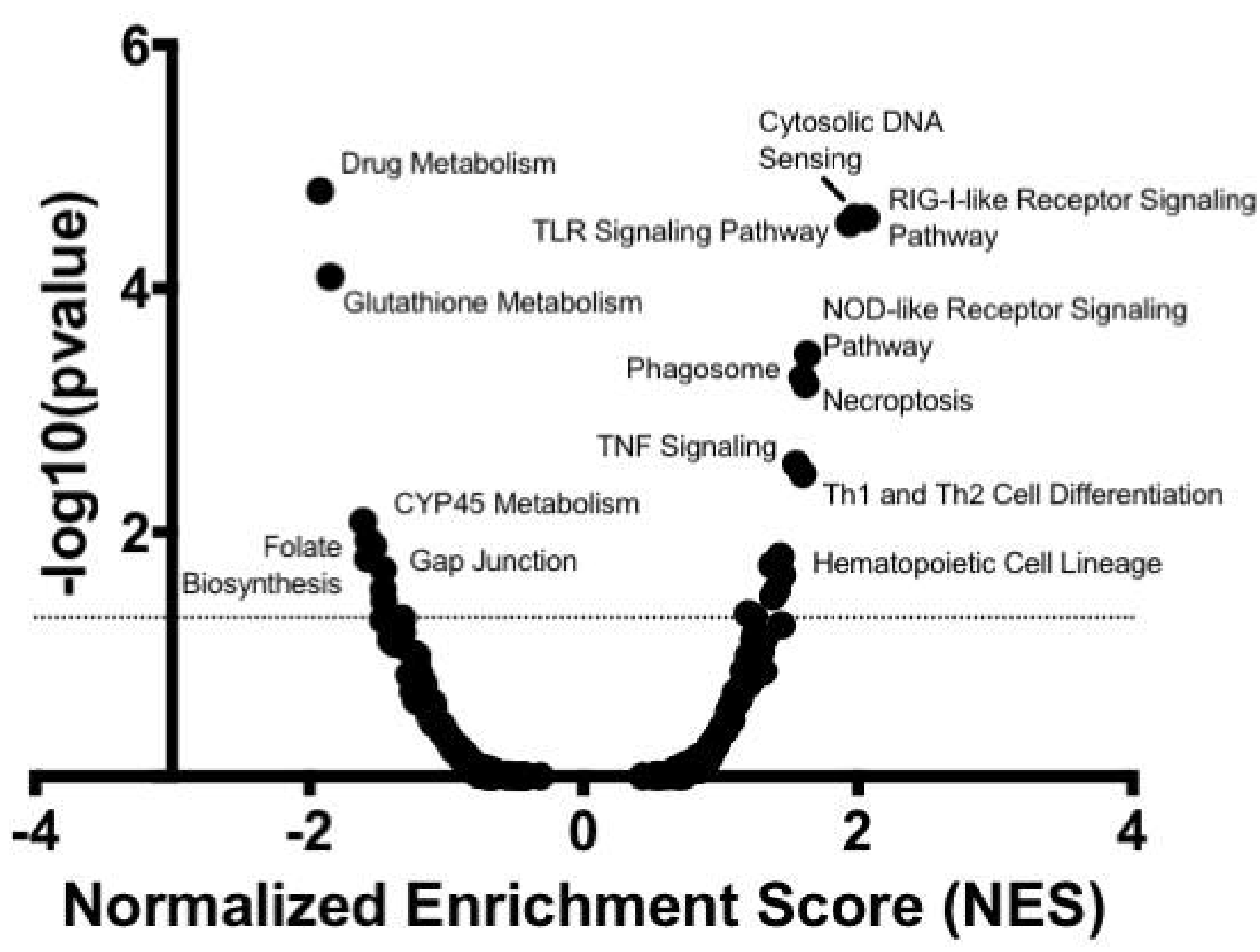

d)

SP-R210_(DN) vs WT Upregulated Disease-

\section{Associated Pathways}

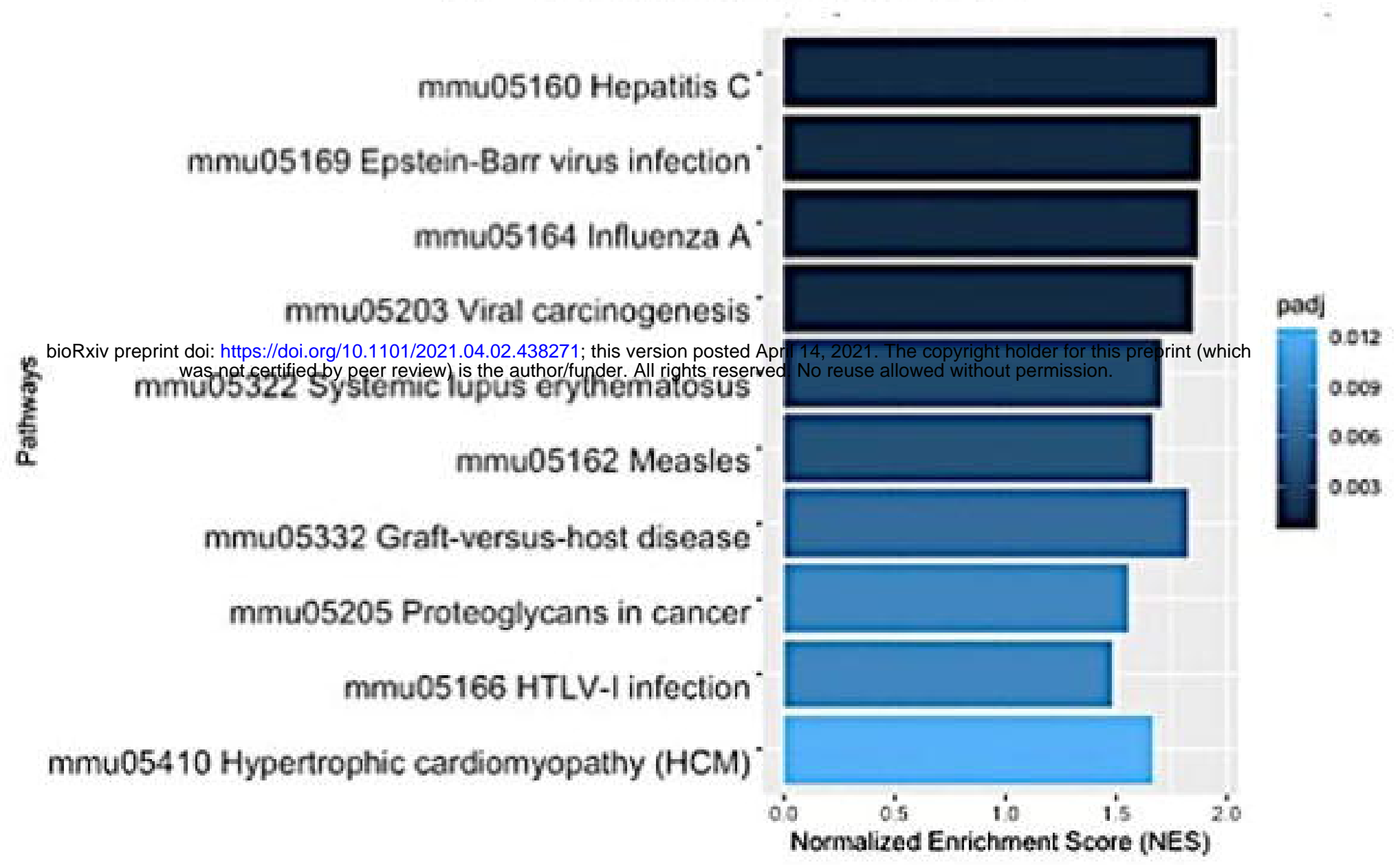

b)

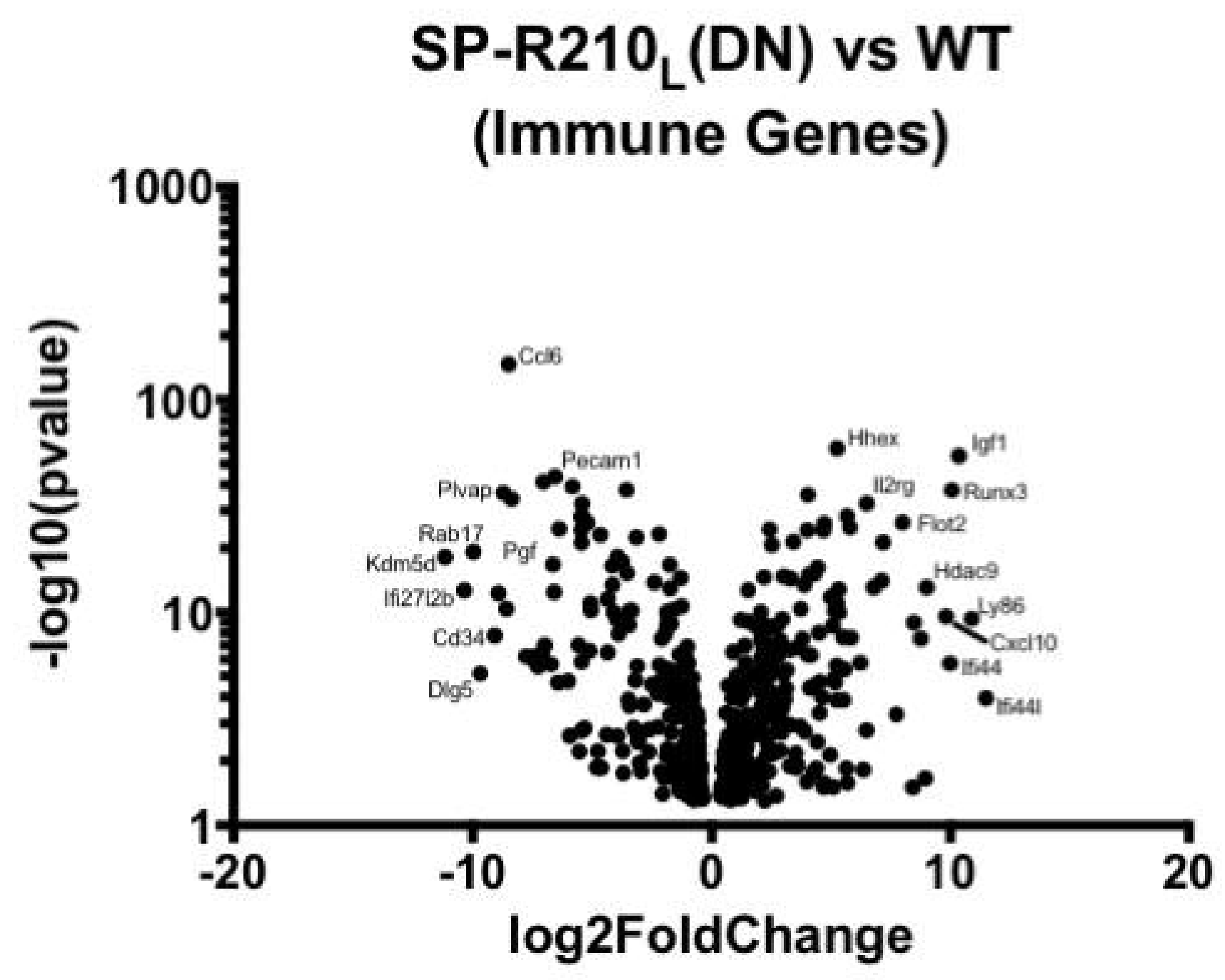

WT Expr. DN Expr.

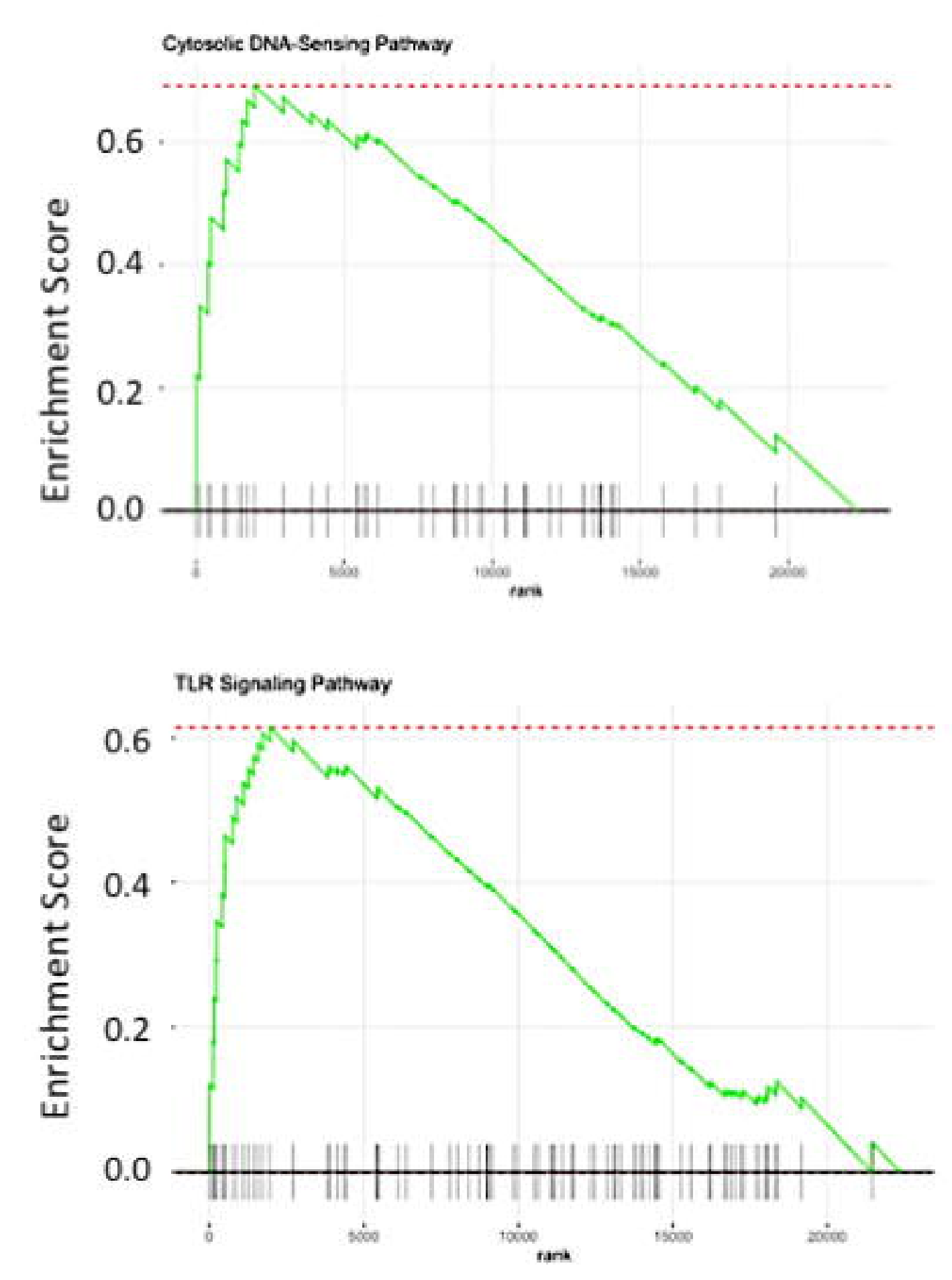




\section{Figure 2}

a)

\section{Peak Consensus: \\ WT vs SP-R210(DN) RAW 264.7 Cells}

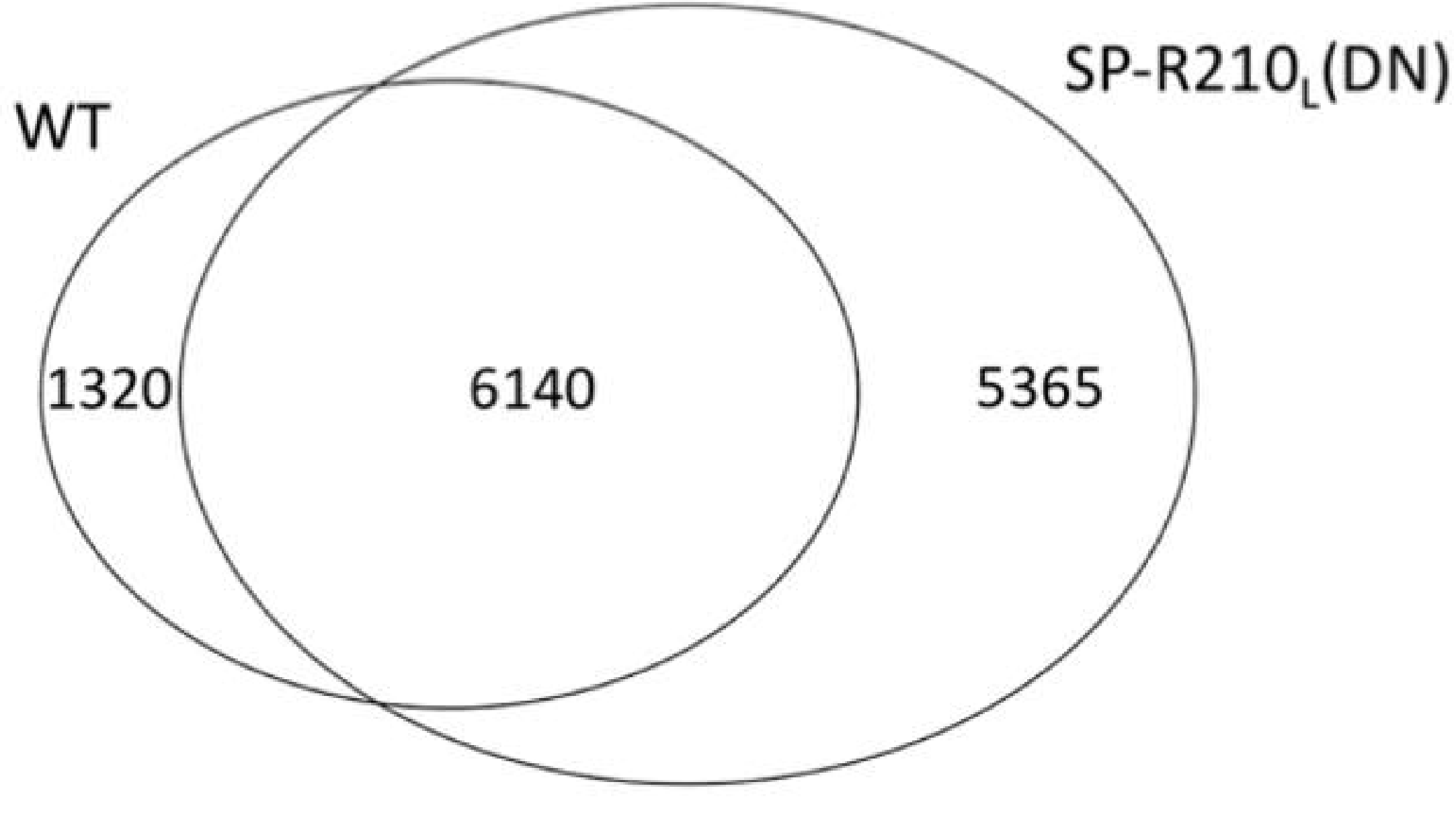

b)

\begin{tabular}{|l|rr|}
\hline & \multicolumn{2}{|c|}{ SP-R210,(DN) } \\
\hline Promoter & $26.11 \%$ & $24.94 \%$ \\
\hline Promoter (<=1 kb) & $17.2 \%$ & $16.06 \%$ \\
Promoter (1-2 kb) & $4.9 \%$ & $4.83 \%$ \\
Promoter (2-3 kb) & $4.01 \%$ & $4.05 \%$ \\
\hline UTR regions & $1.97 \%$ & $2.03 \%$ \\
$\square$ 5' UTR & $0.37 \%$ & $0.34 \%$ \\
\hline 3' UTR & $1.6 \%$ & $1.69 \%$ \\
\hline Exon Regions & $2.4 \%$ & $2.82 \%$ \\
\hline 1st Exon & $0.36 \%$ & $0.38 \%$ \\
\hline Other Exon & $2.04 \%$ & $2.44 \%$ \\
\hline Intron Regions & $33.57 \%$ & $34.64 \%$ \\
\hline 1st Intron & $12.86 \%$ & $12.84 \%$ \\
Other Intron & $20.71 \%$ & $21.8 \%$ \\
\hline Downstream & $1.31 \%$ & $1.23 \%$ \\
\hline Distal Intergenic & $34.63 \%$ & $34.34 \%$ \\
\hline
\end{tabular}
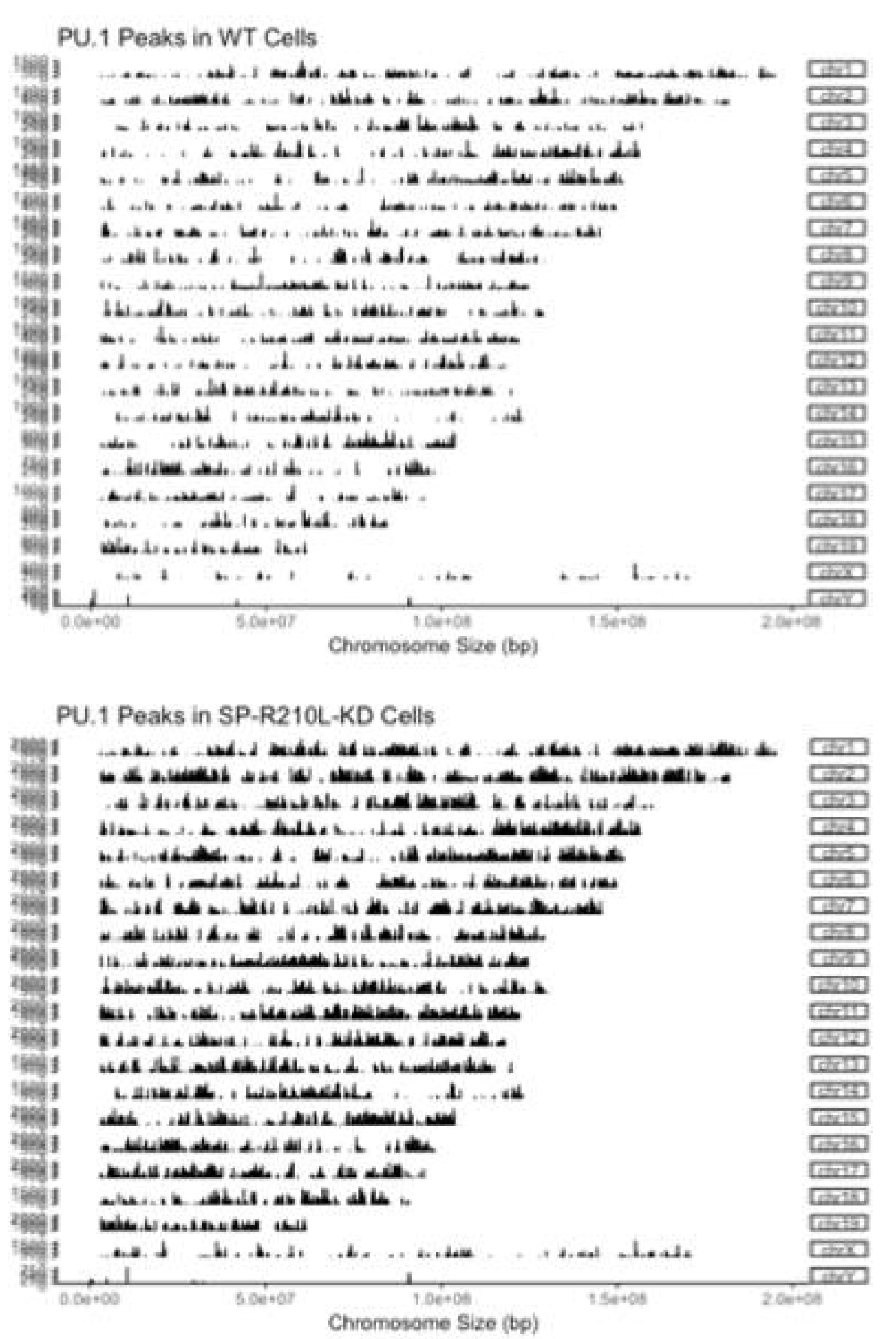

c)

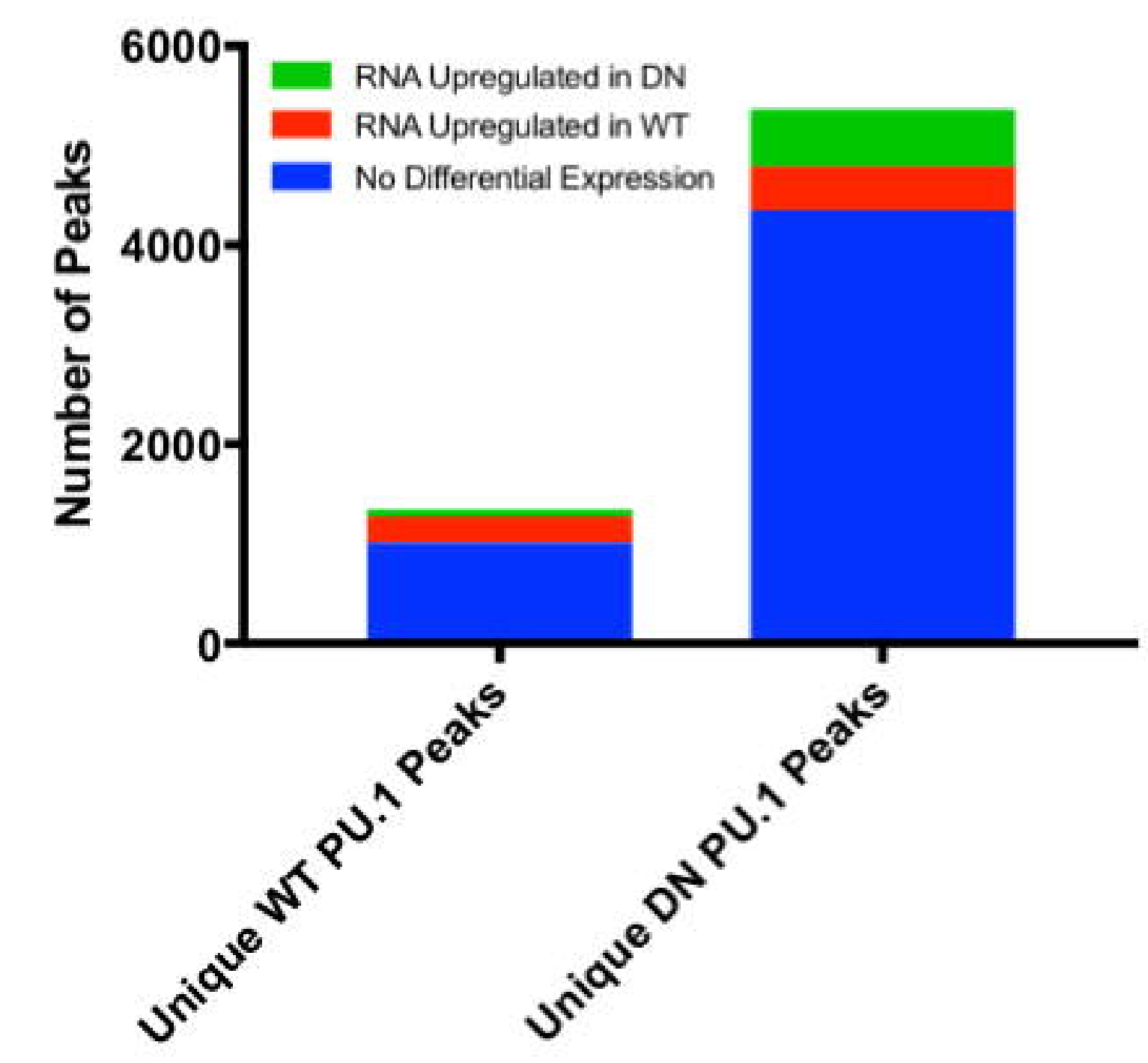

d)

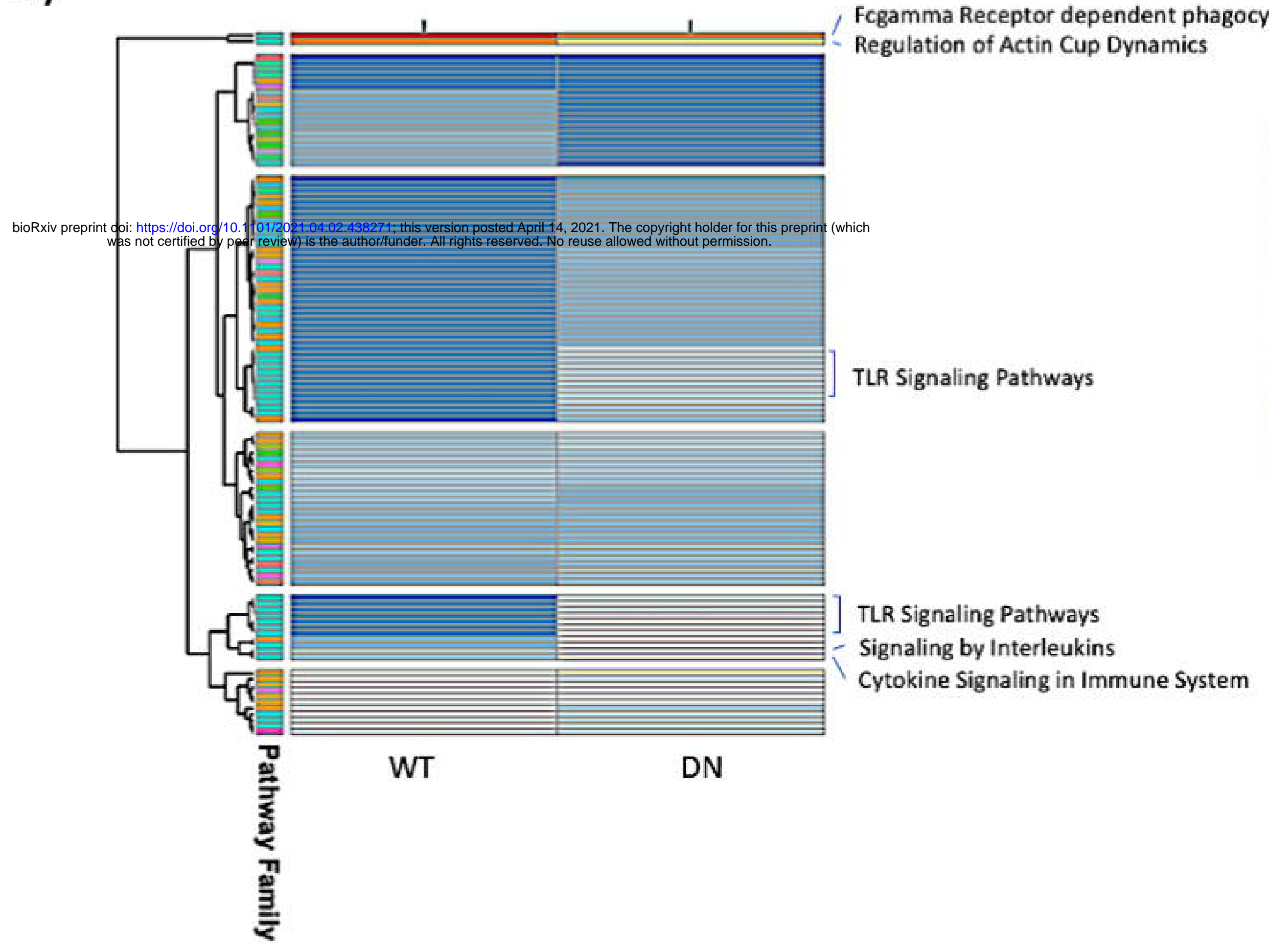


Figure 3

a)

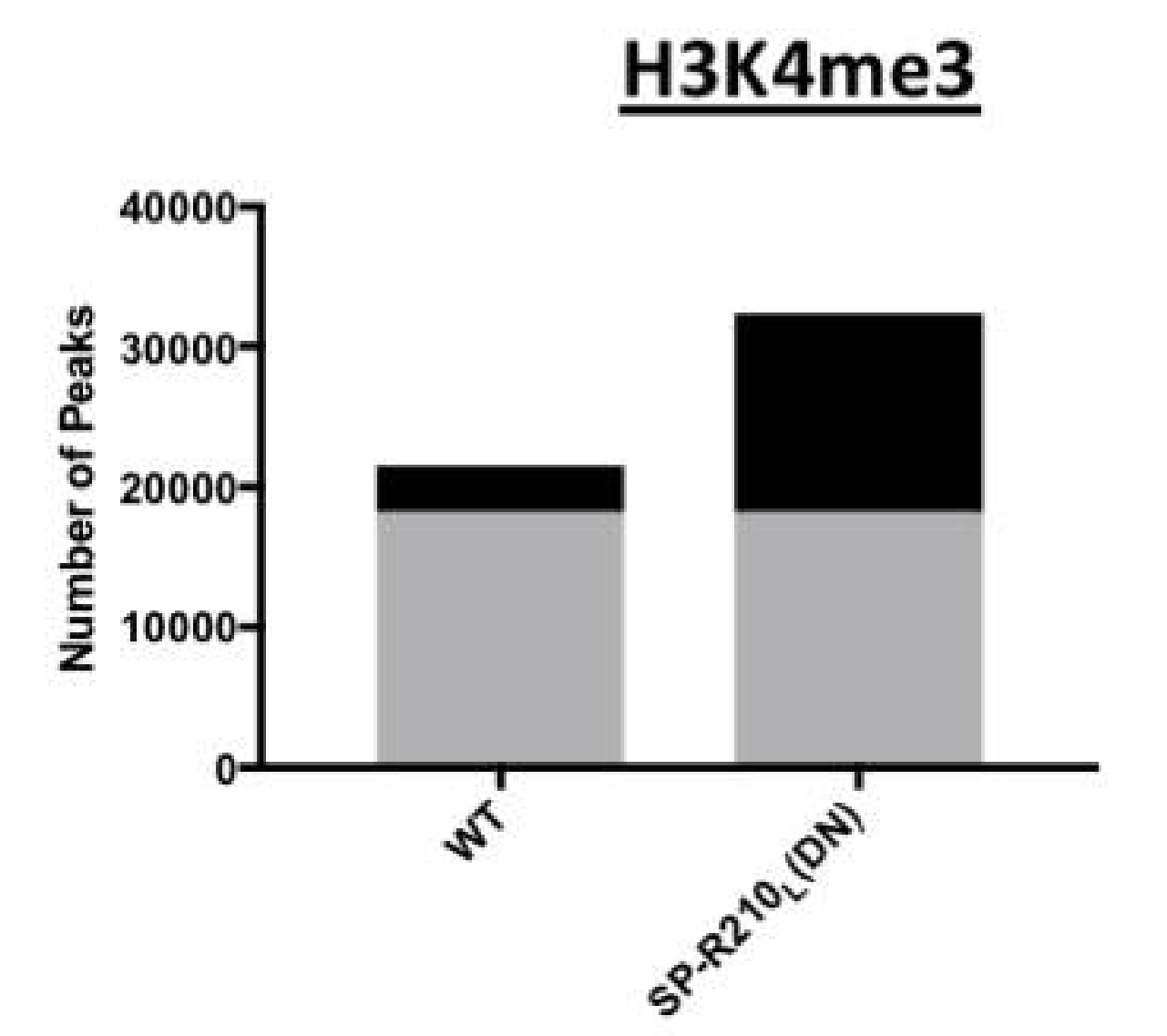

c)

\section{H3K9me3}

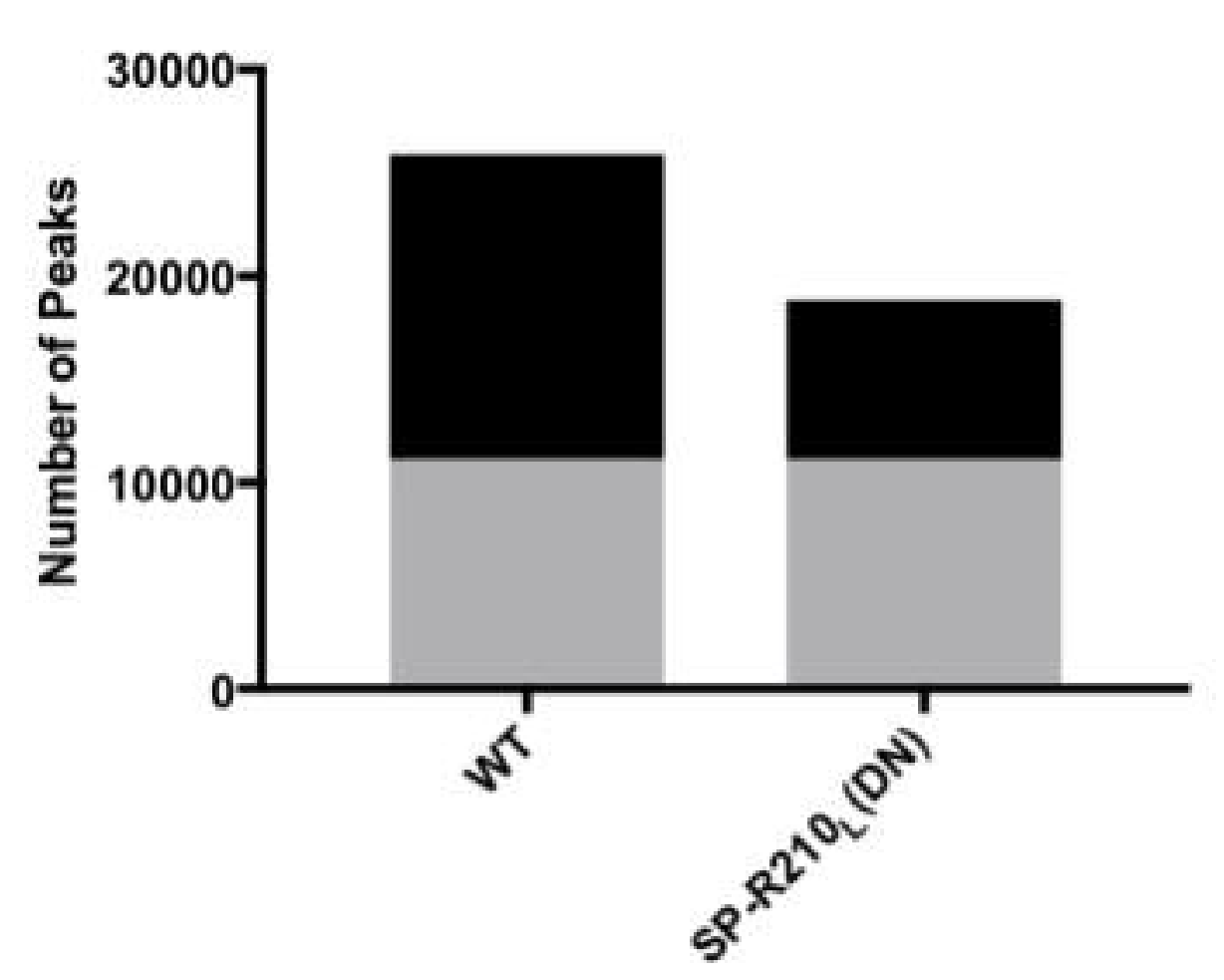

e)

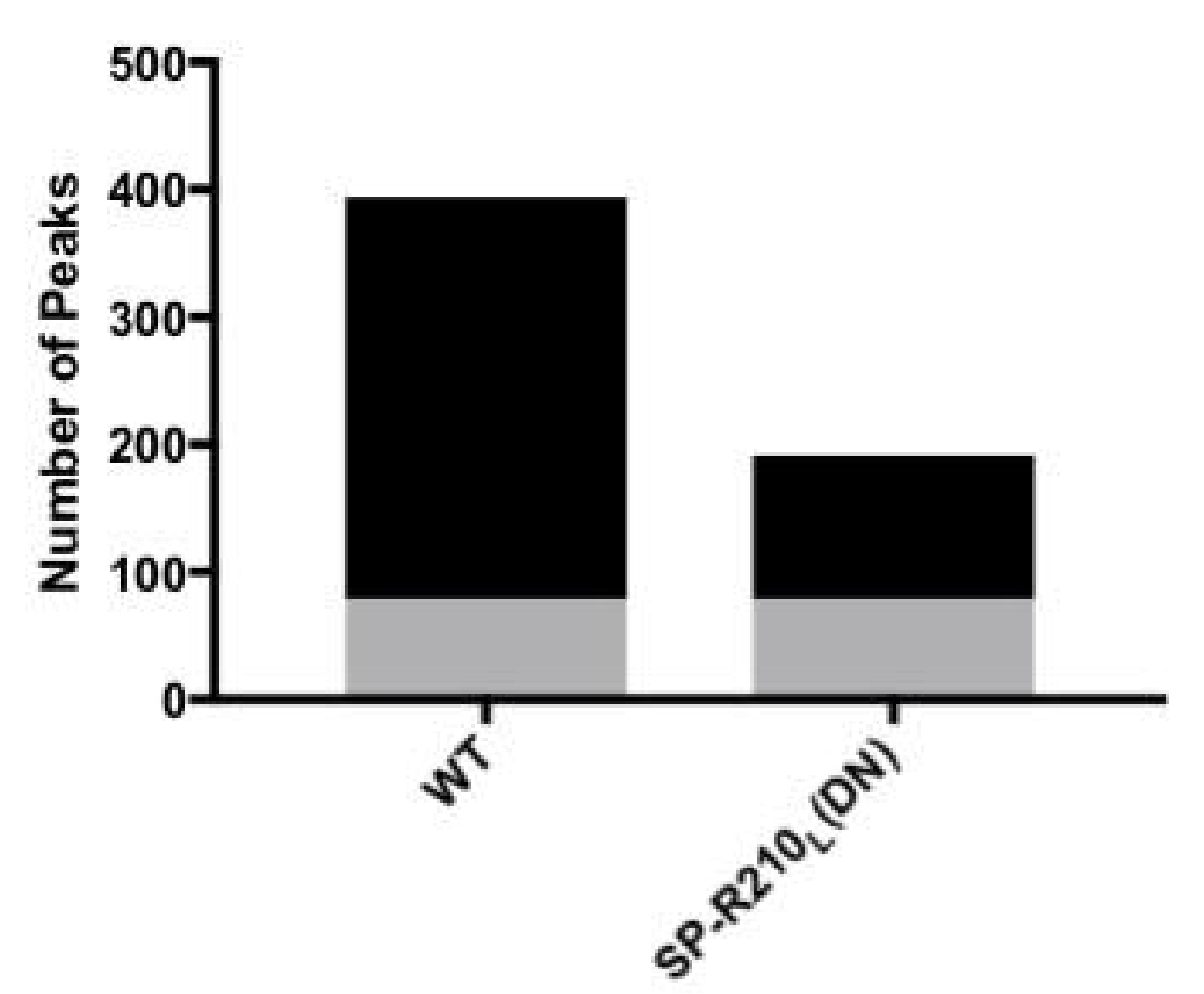

b)

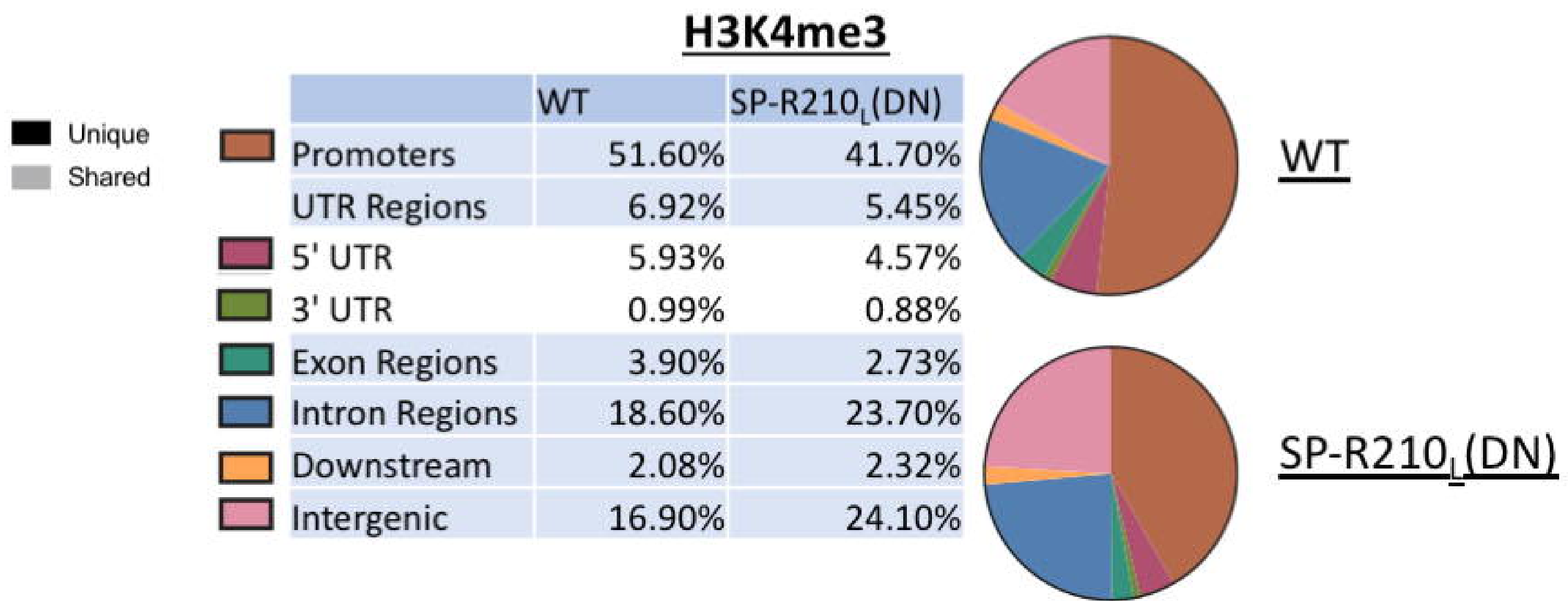

d)

\section{H3K9me3}

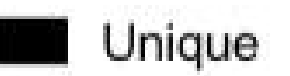
Shared

\begin{tabular}{|c|c|c|}
\hline & WT & SP-R210 (DN) \\
\hline Promoters & $29.30 \%$ & $17.10 \%$ \\
\hline UTR Regions & $6.18 \%$ & $6.97 \%$ \\
\hline 5' UTR & $4.19 \%$ & $5.22 \%$ \\
\hline 3' UTR & $1.99 \%$ & $1.75 \%$ \\
\hline Exon Regions & $7.53 \%$ & $9.19 \%$ \\
\hline Intron Regions & $21 \%$ & $25.50 \%$ \\
\hline Downstream & $2.30 \%$ & $2.14 \%$ \\
\hline Intergenic & $33.60 \%$ & $39.10 \%$ \\
\hline
\end{tabular}

f)

H3K27me3

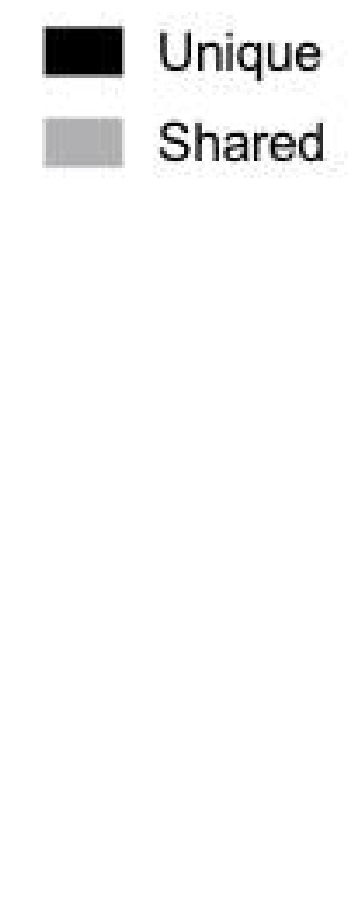

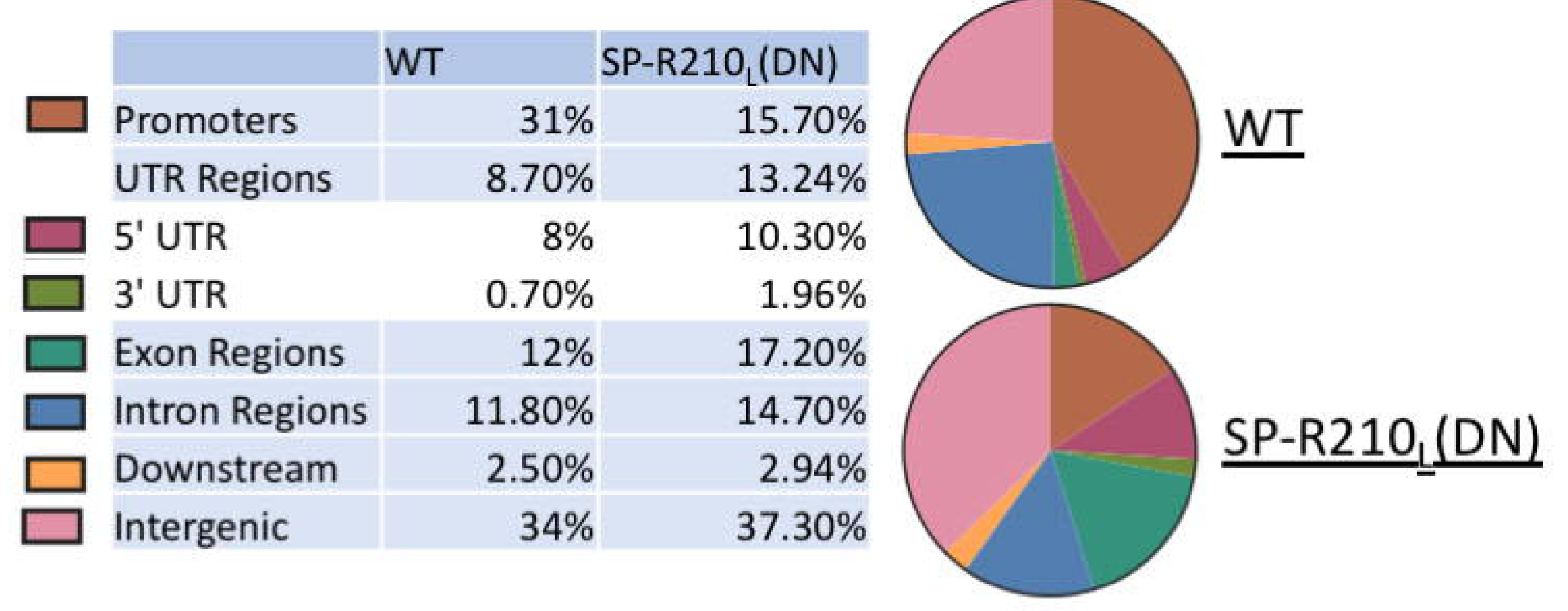

h)

Peak Consensus: H3K4me3 and PU.1 in SP-R210 (DN) Cells

H3K4me3

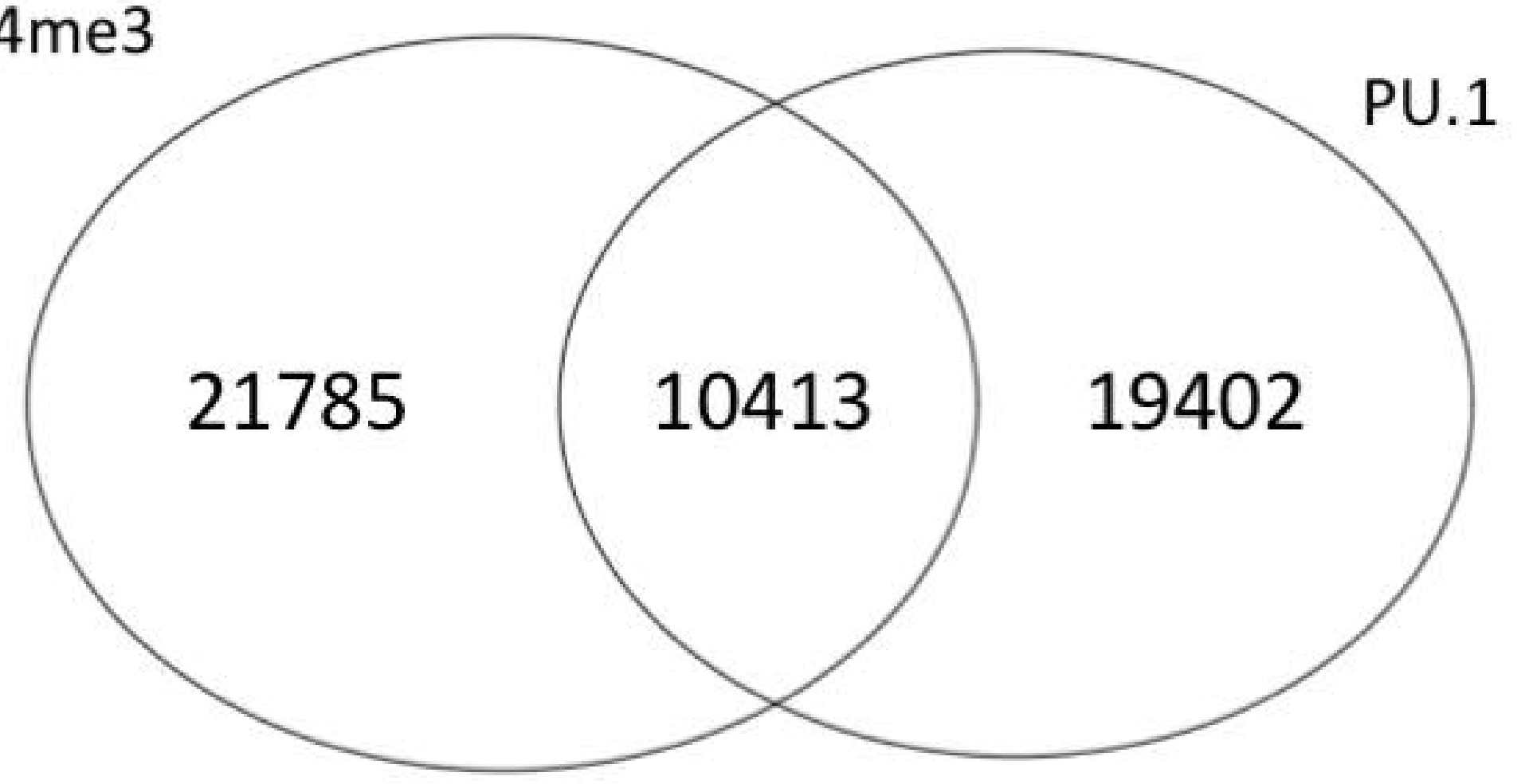


Figure 4

a)

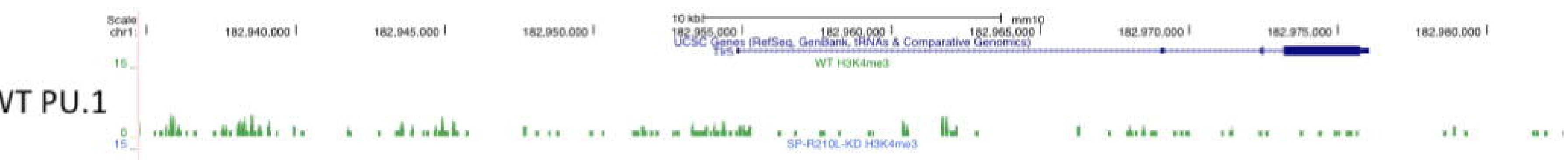

TLR5 WT H3K4me3

DN PU.1

DN H3K4me3

b)

SPI1 (PU.1) WT H3K4me3

DN PU.1

DN H3K4me3

c)

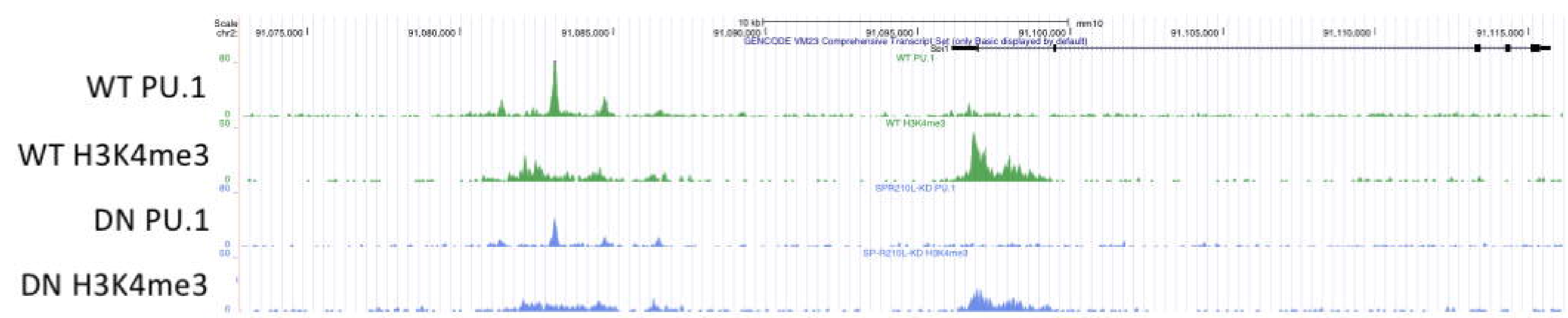

MY018a WT H3K4me3

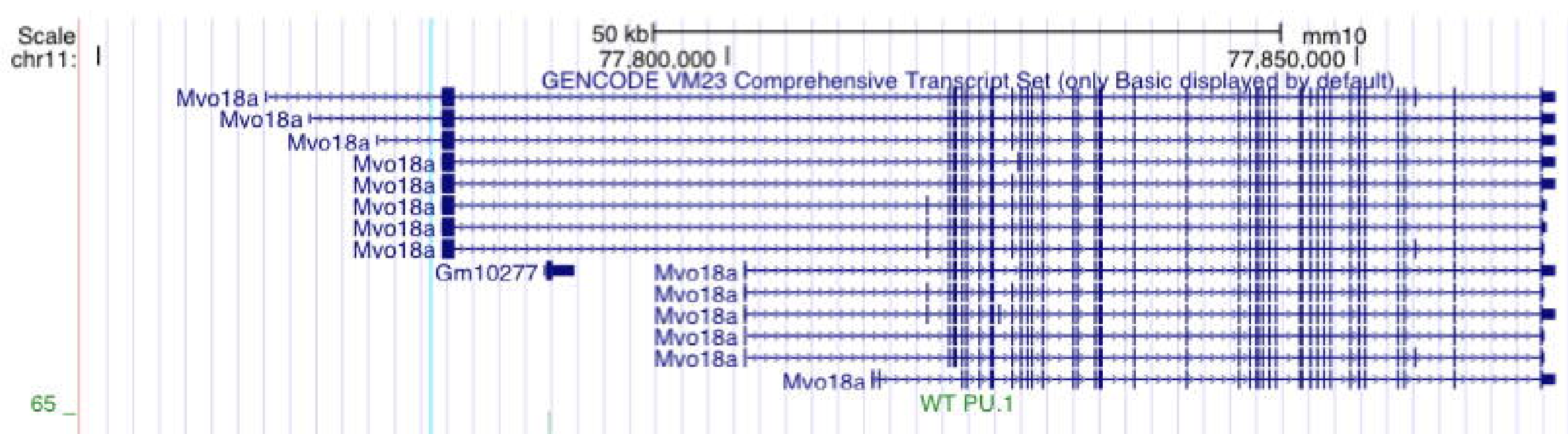

WT PU.1

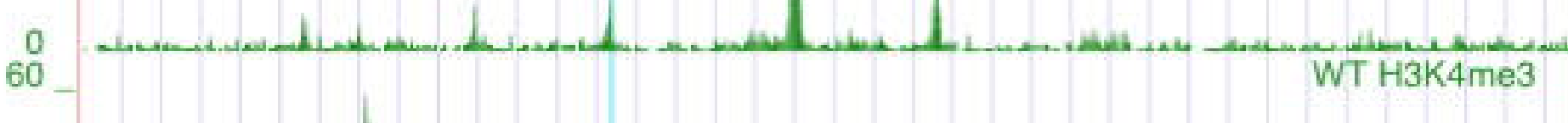

DN PU.1

DN H3K4me3

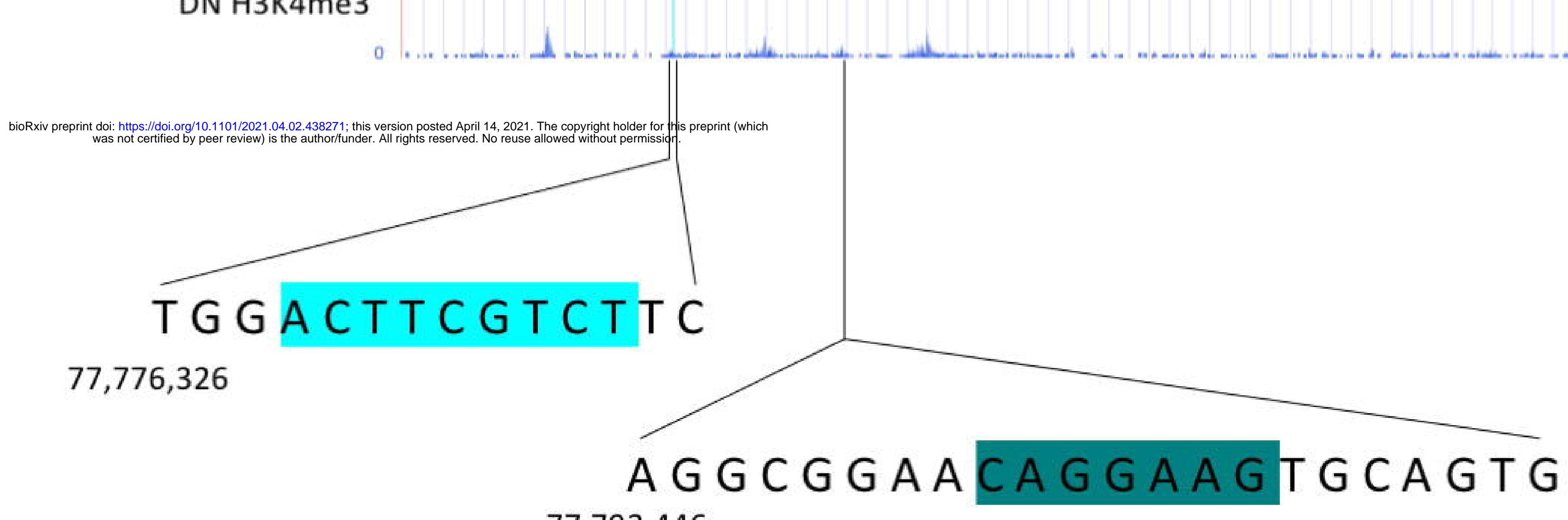
$77,793,446$ 
Figure 5

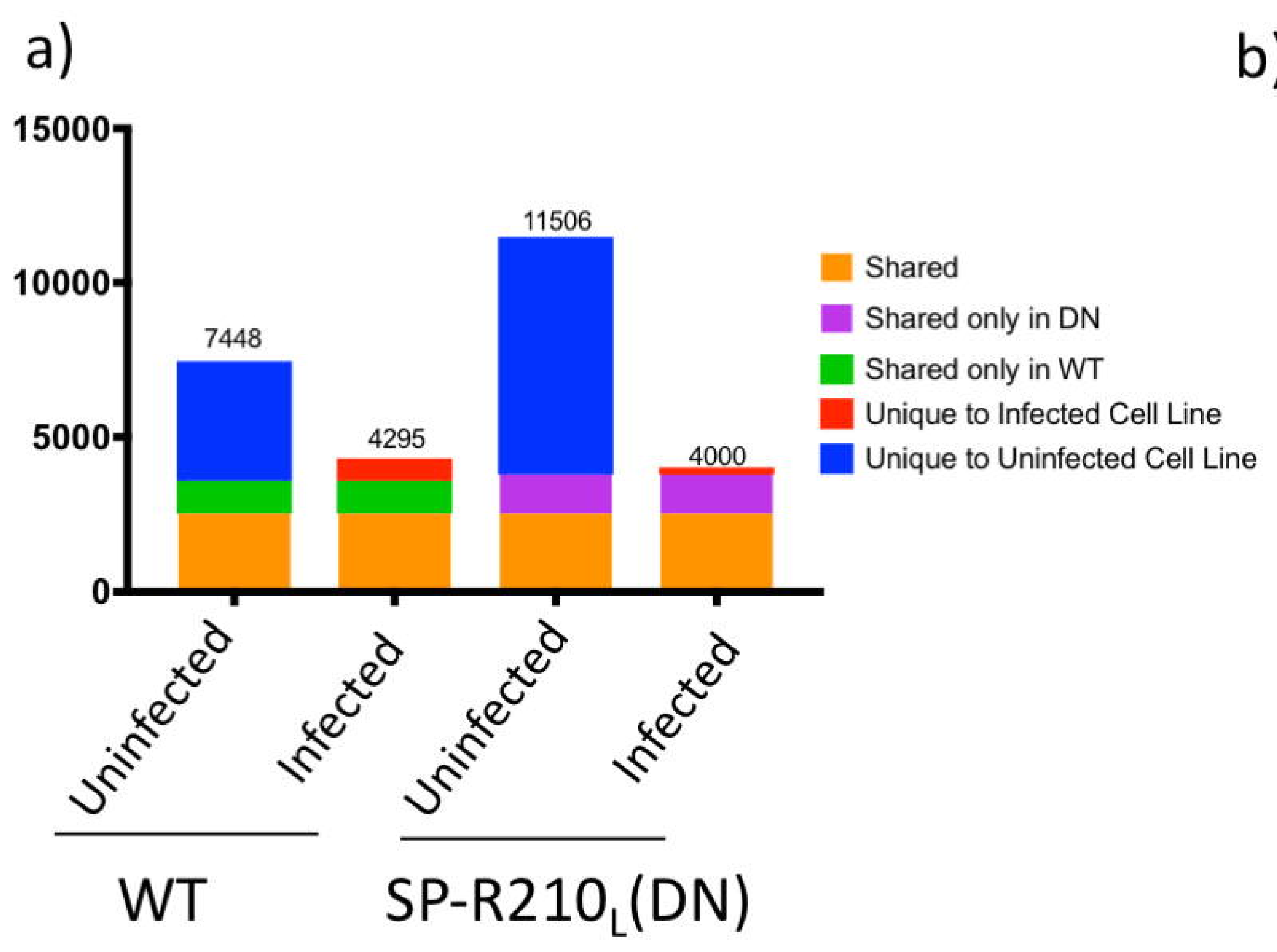

Peak Consensus:

b) Uninfected vs Infected WT RAW 264.7 Cells

Uninfected Infected

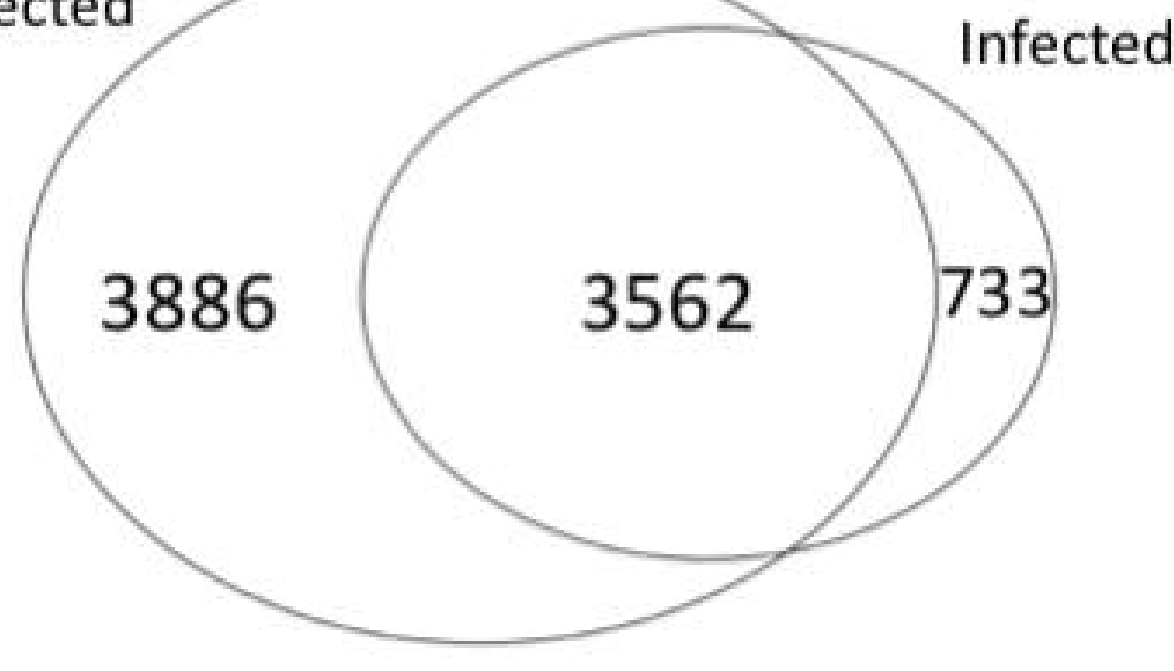

Peak Consensus:

Uninfected vs Infected SP-R210,(DN) RAW 264.7 Cells
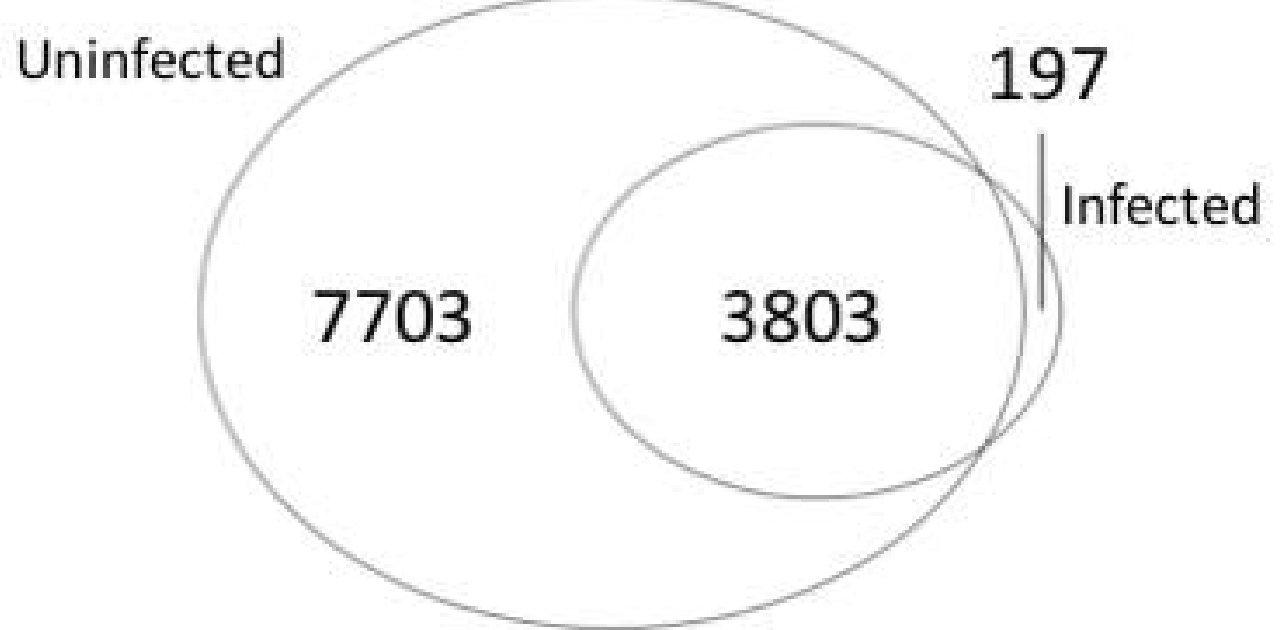

Peak Consensus - WT vs SP-R210,(DN) Infected Cells

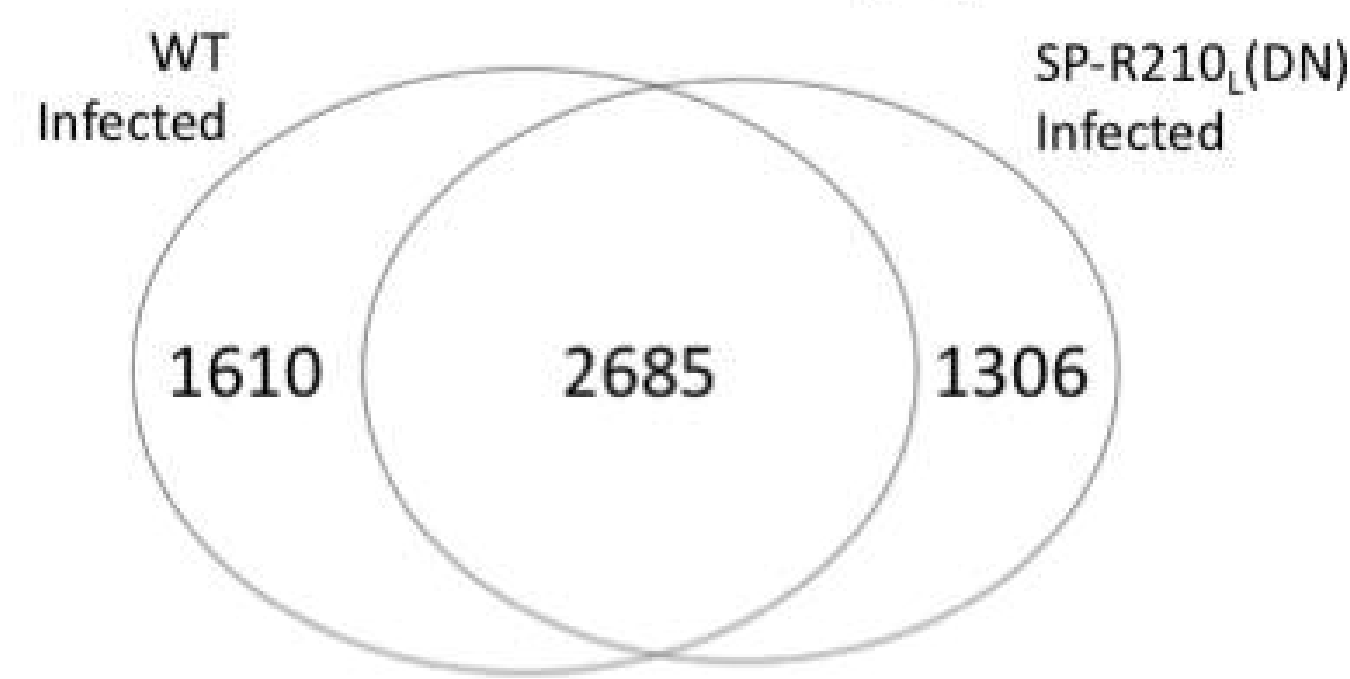

c)

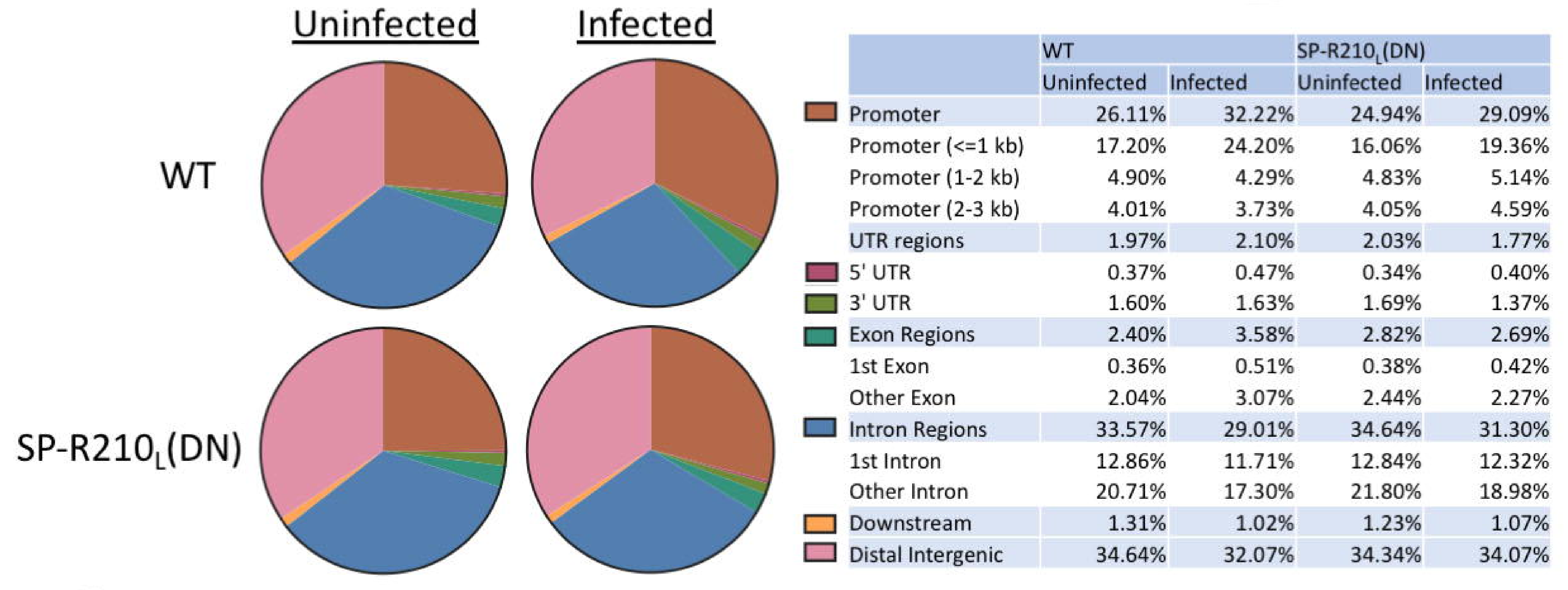

d)

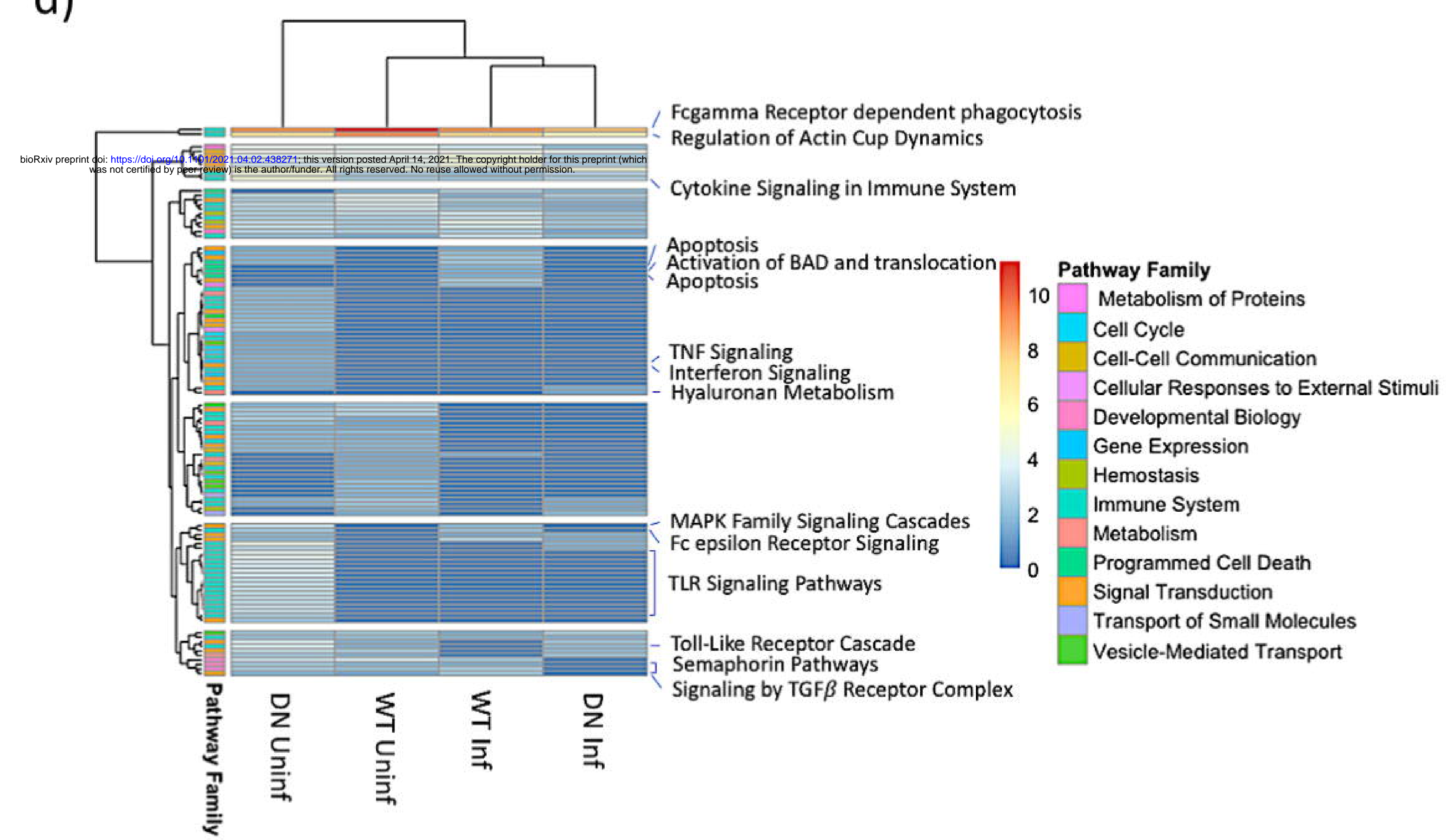


Figure 6

a)

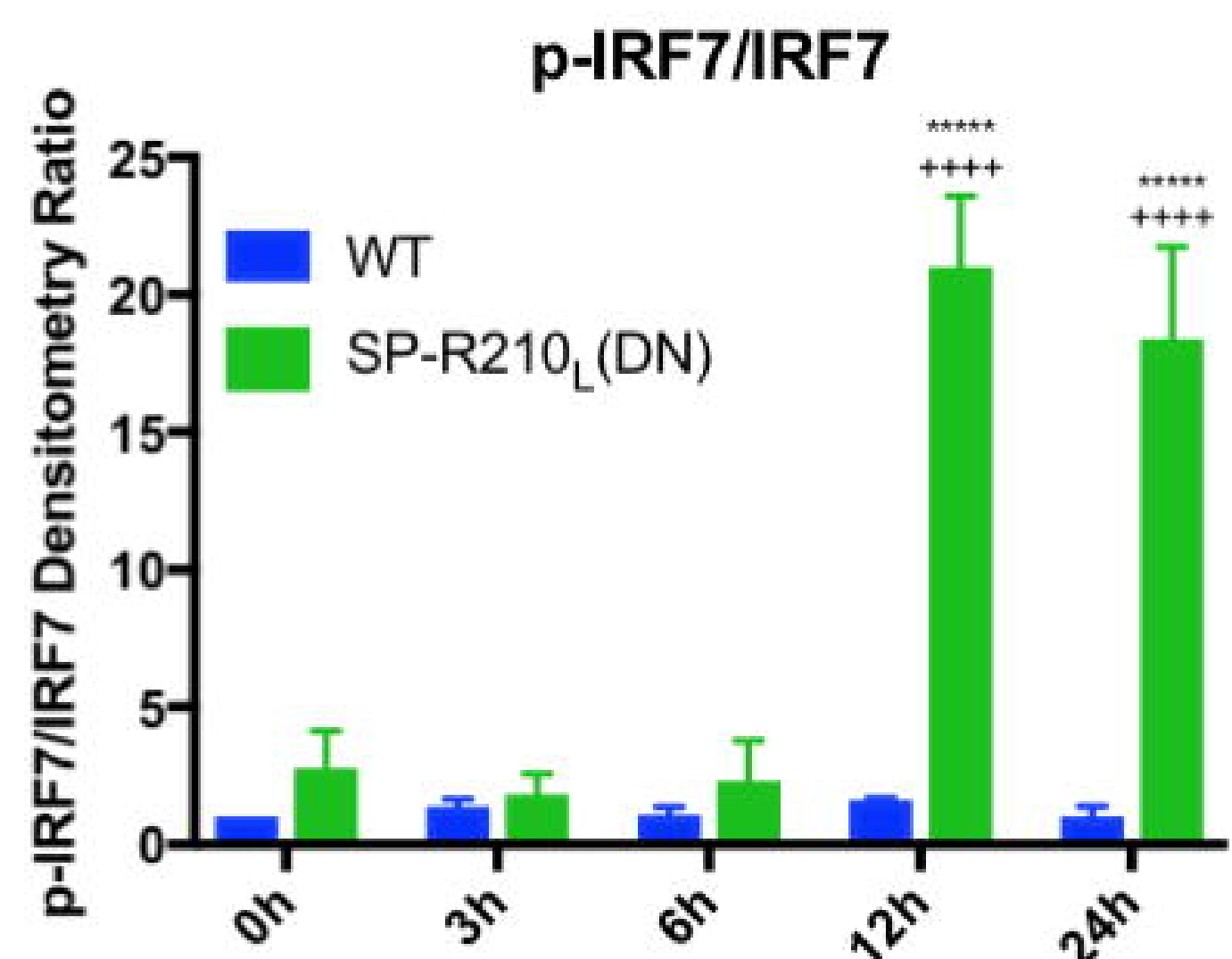

$$
\text { WT }
$$

Uninf $3 \mathrm{HPI} \quad 6 \mathrm{HPI} 12 \mathrm{HPI} 24 \mathrm{HPI}$ p-IRF7

IRF7

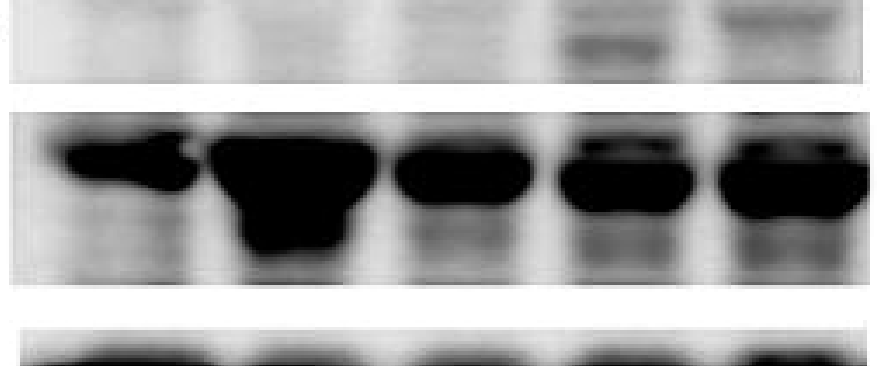

SP-R210 (DN)

GAPDH

c)

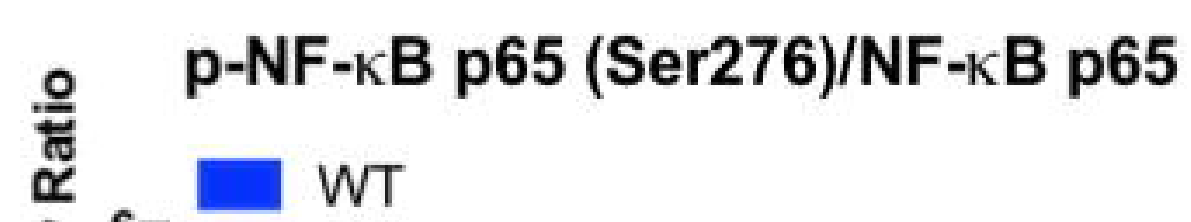$$
\text { 政 }
$$$$
\text { 要 }
$$

$$
\text { WT }
$$
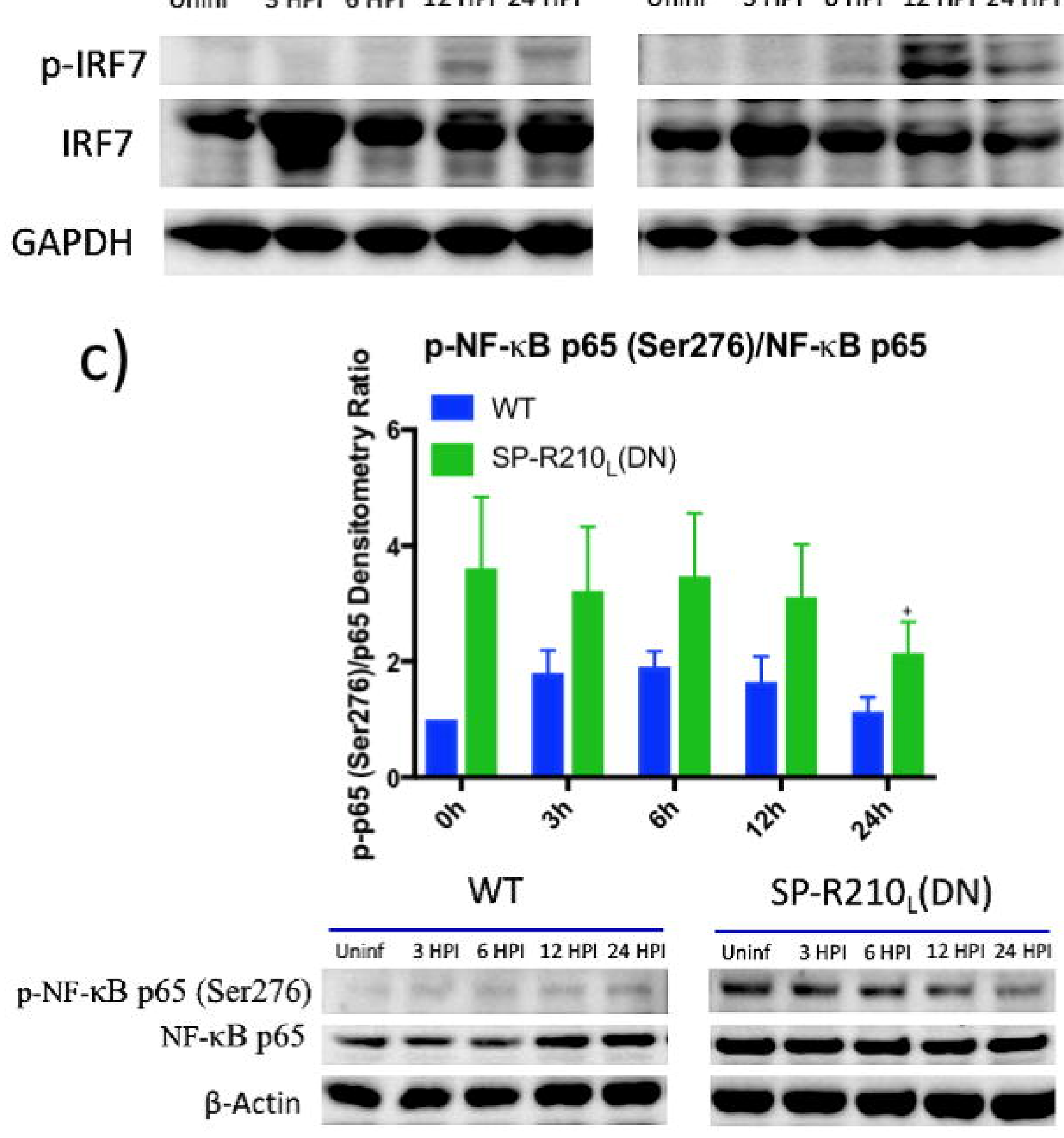

e)

P38-1(p-P38/t-P38)
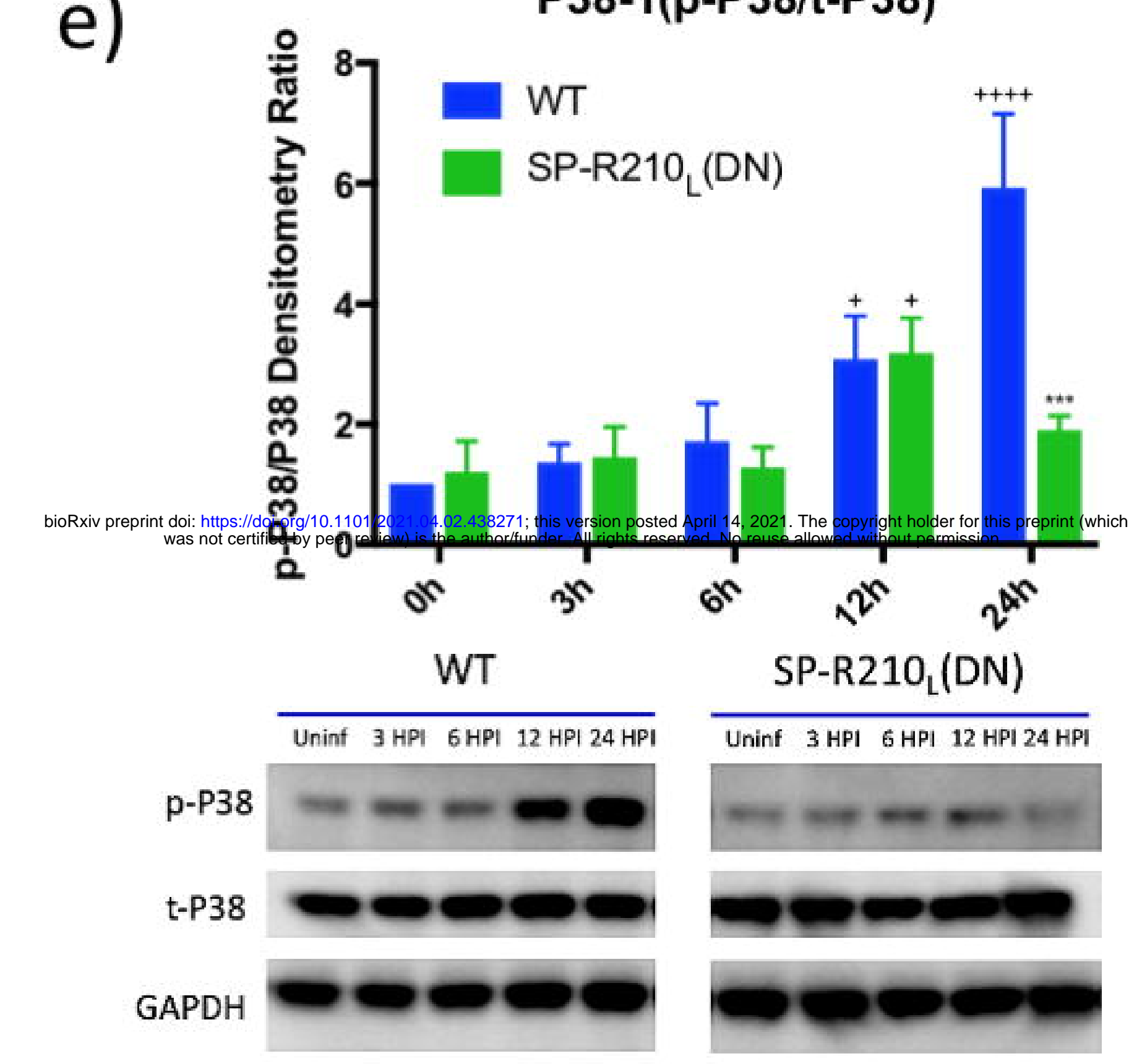

b)
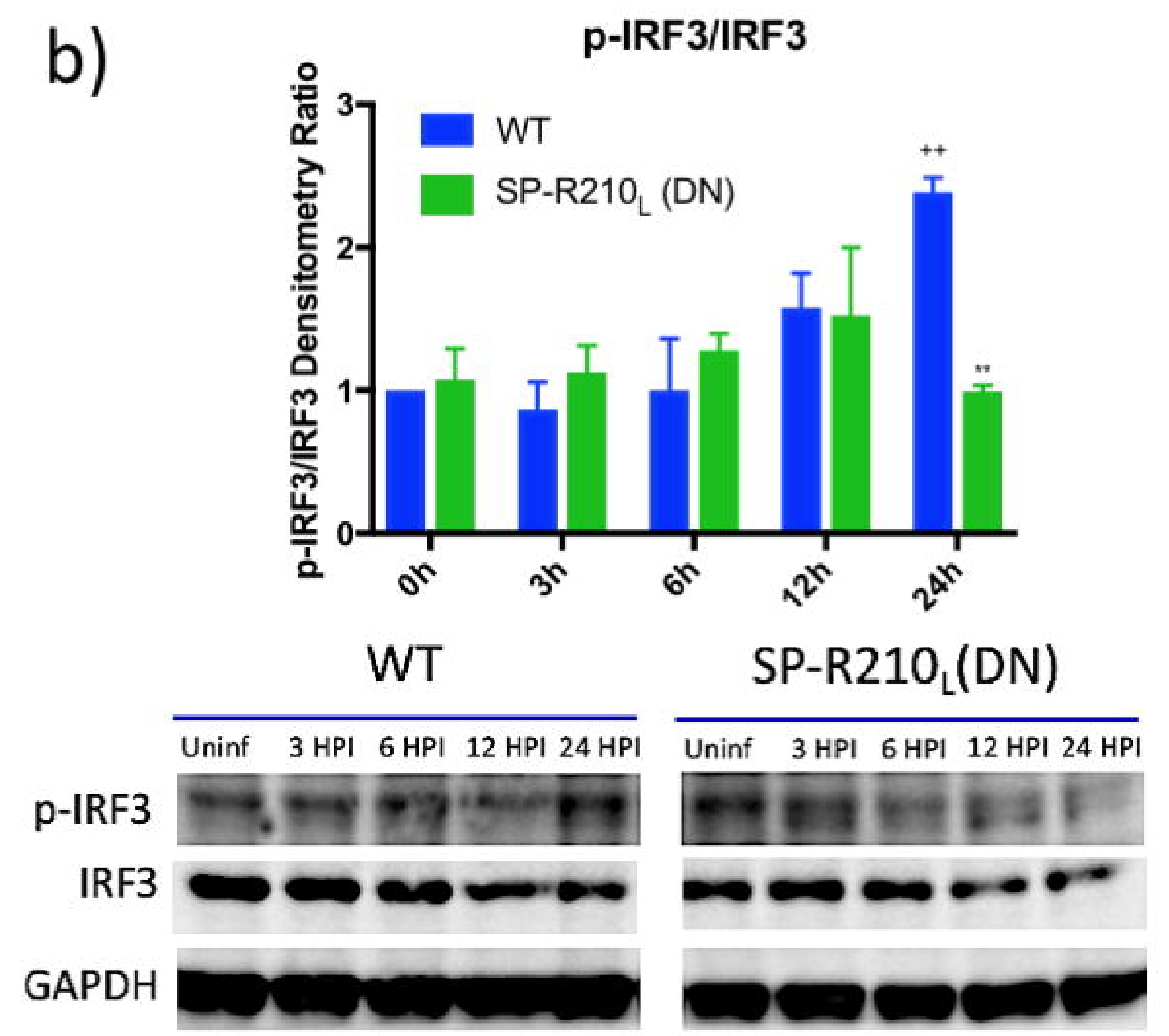

d)
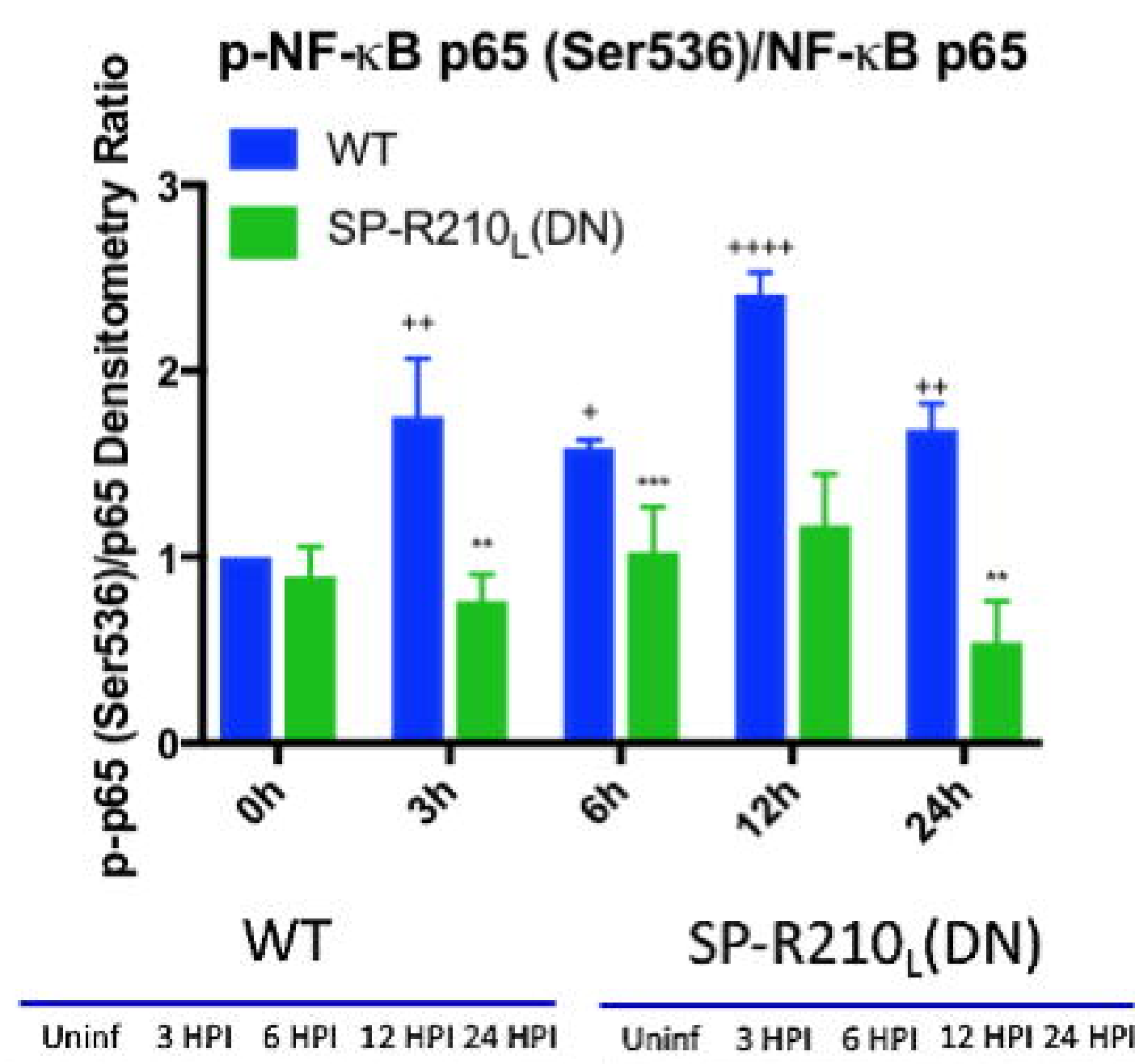

p-NF-кB p65 (Ser536)

NF- $\mathrm{kB}$ p 65

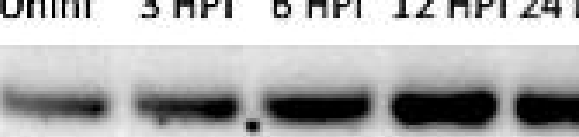

Uninf $3 \mathrm{HPI} 6 \mathrm{HPI} 12 \mathrm{HPI} 24 \mathrm{HPI}$

$\beta$-Actin 